Revista de Derecho

Universidad Católica del Norte

Sección: Estudios

Ańo 18 - No 2, 2011

pp. $151-188$

\title{
TRABAJADORES INVENTORES: TITULARIDAD DE SUS CREACIONES Y RÉGIMEN RETRIBUTIVO*
}

\section{ALFREDO SIERRA HERRERO ${ }^{* *}$}

RESUMEN: El desarrollo de invenciones se reconoce como un elemento clave del progreso técnico y económico. En su gran mayoría, estas son desarrolladas en el seno de empresas o entidades, que se valen de trabajadores dependientes para enfrentar tales tareas. Los actores principales son, entonces, las partes clásicas de una relación laboral: empleador y trabajador. Se trata de una materia que debe compatibilizar de forma equilibrada ambos intereses, pues si su tratamiento se presenta inadecuado para uno de ellos, puede producir un desincentivo generalizado de la investigación.

PALABRAS CLAVE: Investigación - inventos - propiedad industrial trabajador - empresa.

\section{INVENTORS WORKERS: OWNERSHIP OF THEIR CREATIONS AND COMPENSATIONS}

ABSTRACT: The development of inventions is recognized as a key element in technical and economic progress. Mostly, they are developed within companies or entities that entrust their employees with such tasks. The main parties therein are, thus, the parties of a work relationship, i.e. employer and employee. It is a subject in which both interests must be correctly balanced, as an inadequate treatment regarding either one of them, may produce a widespread disincentive to research.

KEY WORDS: Research - inventions - industrial property - employee - enterprise.

\footnotetext{
* La redacción de este artículo ha contado con la ayuda del Fondo Nacional de Ciencia y Tecnología de la República de Chile, en el marco del Proyecto Fondecyt $N^{\circ} 11100220$, titulado "Régimen jurídico de las invenciones de los trabajadores", en el cual el autor es investigador responsable.

Fecha de recepción: 2 de agosto de 2011

Fecha de aceptación: 11 de noviembre de 2011.

** Licenciado en Ciencias Jurídicas y Sociales, Universidad de Chile. Abogado. Doctor en Derecho por la Universidad de Santiago de Compostela. Profesor de Derecho del Trabajo, Universidad de Los Andes (CHILE). Correo electrónico: asierra@uandes.cl
} 


\section{INTRODUCCIÓN}

El Derecho de la Propiedad Industrial se origina como un Derecho orientado al fomento de la investigación, cuyo objetivo consiste en la obtención y desarrollo de invenciones en diferentes campos. La mayoría de las investigaciones, dados los costos implicados, se producen en el seno de empresas privadas o públicas y en las universidades por personal contratado para ello. En efecto, las condiciones económicas, materiales y personales que hoy requiere la investigación suelen no estar al alcance de un solo individuo. Las empresas u otras entidades son entonces las que proporcionan dichas condiciones, ya que la organización de capital y trabajo que comprenden, puede enfrentar con mayor éxito desafíos de esta naturaleza ${ }^{1}$.

Se advierte así que en tales invenciones concurren frecuentemente dos partes; por un lado, la empresa o entidad pública o privada, entre cuyos objetivos se encuentra el desarrollo de la investigación; y, por otro, los trabajadores de las cuales se valen tales entidades para llevar a cabo dichas tareas. Como se observa, se trata de una materia que debe compatibilizar de forma equilibrada ambos intereses: el del empresario y el de los trabajadores. $\mathrm{Y}$ es que si su tratamiento se presenta inadecuado para uno de ellos, puede producir un desincentivo a la investigación en términos generales, con todos los perjuicios que esto puede ocasionar.

El análisis jurídico de los inventos de trabajadores es un tema interesante no solo por su trascendencia práctica, sino también porque implica un estudio interdisciplinario, pues en él confluyen tanto el Derecho Comercial (Propiedad Industrial) como el Derecho del Trabajo. Se advierte así como esta materia es estudiada en el Derecho comparado tanto por especialistas de Derecho del Trabajo ${ }^{2}$ como de Derecho Comercial ${ }^{3}$ e, incluso, en el marco de investigaciones de tipo conjunto ${ }^{4}$.

1 Véase Gridel, Jean-Pierre (1980). Les inventions de salariés à l'épreuve de la loi du 13 juillet 1978 et du Décret du 4 septembre 1979, París: Librairie générale de Droit et de jurisprudence, 79 pp., pp. 13 ss.

2 Véase, entre otros, Alonso Olea, Manuel (1987). "Invenciones laborales". En Alonso Olea, Manuel et al. Jornadas sobre la nueva ley española de patentes: Tecnologí, industria y patentes en la España comunitaria: ciclo de doce conferencias presentadas los días 14 y 15 de mayo de 1986. Barcelona: Grupo español de la AIPPI, pp. 87-94; y Albiol Montesinos, Ignacio (1975). "Los inventos del trabajador, el socio industrial y la ejecución de obra". Revista de Derecho Privado, pp. 109-126.

3 Véase, entre otros, Bercovitz Rodríguez-Cano, Alberto (1976). "Anotaciones a la regulación legal española sobre invenciones laborales". Actas de derecho industrial y derecho de autor, T. III, pp. 49-91; y Gómez Segade, José Antonio (1984). "El derecho a la patente". En Gómez Segade, José Antonio. y Fernández-Novoa, Carlos. La modernización del Derecho español de patentes. Madrid: Montecorvo, pp. 103-138.

4 Véase Sala Franco, Tomas y Vicent Chuliá, Francisco (1988). "El nuevo régimen jurídico de las invenciones laborales". Actualidad Laboral, N 4, pp. 1.977-1.999. 
El presente artículo tiene por finalidad analizar precisamente la regulación de nuestra Ley de Propiedad Industrial (Ley 19.039, en adelante "LPI") sobre las invenciones desarrolladas por personas dentro del ámbito de las empresas o entidades en las que prestan sus servicios. Estas invenciones son reglamentadas en el Título VI de la LPI, donde reciben la denominación de "invenciones en servicio" (arts. 68 a 72). A este respecto, es necesario hacer presente una acotación en el alcance de este trabajo, aunque las normas indicadas regulan la situación tanto de trabajadores dependientes, como de personas que han sido contratadas a través del contrato de arrendamiento de servicios, ambos casos presentan significativas diferencias que justifican su tratamiento por separado. Por tal razón, abordaremos exclusivamente la situación de los trabajadores dependientes y dejaremos el análisis de los prestadores de servicios para un estudio posterior.

Nuestra exposición se dividirá en dos partes. En la primera, trataremos la atribución de titularidad de los inventos desarrollados por trabajadores (denominados "invenciones en servicio"). En este sentido, veremos que en el ordenamiento nacional existe una gran distinción entre la denominada "invención contratada o por encargo" (art. 68 LPI), vinculada a la prestación debida por un contrato de trabajo y que pertenece al empresario, y la "invención libre" (art. 69 inc. $1^{\circ}$ LPI), desligada de dicho contrato, que pertenece al trabajador. Se ańade a estas dos, otro tipo de invención conocida como "mixta" (art. 69 inc. $2^{\circ} \mathrm{LPI}$ ), cuya la titularidad se concede al empresario, si el trabajador la consigue, pese a no estar contratado para ello, beneficiándose de los medios y conocimientos adquiridos en la empresa. En la segunda parte del trabajo, examinaremos el problema de las remuneraciones que se generan para aquellos trabajadores que obtienen una invención. En particular, centraremos nuestra atención en la denominada retribución adicional, propia del trabajador-inventor, y que resulta sumamente interesante pues presenta una serie de aspectos novedosos que escapan de los criterios comunes de las remuneraciones contenidas en el Código del Trabajo (en adelante, CdT).

\section{1) ANTECEDENTES NORMATIVOS}

La regulación de las invenciones de los trabajadores ha sido fruto de una lenta y laboriosa evolución ${ }^{5}$, en donde se perciben los esfuerzos por superar una tensión social, a través de la definición de derechos y deberes de

5 Véase Lois Bastida, Fátima (2000). La protección del inventor asalariado. Madrid: Civitas, 290 pp., p. 39. 
empleadores y trabajadores ${ }^{6}$. Su origen se encuentra en la necesidad histórica surgida durante el siglo XIX, tanto en el Derecho europeo como norteamericano, dado que sus regulaciones sobre Propiedad Industrial no contenían normas especiales en los casos que el inventor era un trabajador, razón por la cual el contrato se constituyó como la primera forma de reglamentación ${ }^{7}$. Este régimen de libertad contractual permitió que los empleadores comenzaran a establecer cláusulas en los contratos de trabajo, mediante las cuales los trabajadores les cedían la titularidad de las futuras invenciones obtenidas en la empresa, sin otorgarles en muchos casos una retribución justa ${ }^{8}$.

Los problemas creados por estas cláusulas generales de cesión fueron abordados por la jurisprudencia comparada, que conoció de una serie de litigios promovidos por trabajadores-inventores en contra de sus empleadores. Surgieron así los primeros criterios que determinaban la eficacia de tales cláusulas, como igualmente los derechos que correspondían a quienes no se les concedía la titularidad de la invención ${ }^{9}$. En tanto, la doctrina comenzó a complementar la labor judicial, definiendo no solo los derechos del trabajador-inventor, sino que incluso impulsando reformas legales que incluyeran disposiciones acerca de esta particular clase de invenciones. La tarea iniciada por la doctrina alemana, que tuvo su consagración en el Congreso de Augsburgo de la Asociación alemana para la Protección de la Propiedad Industrial -celebrado el año 1914-, terminó siendo rápidamente seguida por los demás ordenamientos europeos ${ }^{10-11}$.

$6 \quad$ Véase Bercovitz (1976) 67, para quien esta regulación debe considerar "los intereses de todas las partes implicadas a la hora de atribuir los derechos y las ventajas derivadas de las invenciones conseguidas".

LoIs (2000) 34 .

LoIs (2000) 35

Véase, desde el Derecho estadounidense, Fisk, Catherine (1998). "Removing the "Fuel of Interest' from the 'Fire of Genius': Law and the Employee-Inventor, 1830-1930". The University of Chicago Law Review, Vol. 65, $\mathrm{N}^{\circ}$ 4, pp. 1.127-1.198. La autora, en un acabado análisis de la jurisprudencia norteamericana en el período 1830-1930, señala que en los primeros fallos que analizaban cláusulas contractuales que asignaban las invenciones de un trabajador a su empleador (1860-1920), los tribunales "se mostraron reacios a considerar que tal acuerdo existía, a menos que la evidencia fuera clara, y cuando existía tal acuerdo, la mayoría de los tribunales lo entendían estrictamente en contra del empleador" (p. 1.184) (la traducción es nuestra). Desde el Derecho europeo, LoIs (2000) 35-36.

10 Véase Lois (2000) 36-37; y EstupiñÁn CÁceres, Rosalía (2003). Las invenciones laborales en la empresa. Madrid: Edersa, 346 pp., p. 62.

11 El primer cuerpo legal que se refirió expresamente a esta materia fue la Ley austríaca de Patentes del 11 de enero del ańo 1897 que, reconociendo la dependencia económica de los trabajadores con respecto a sus empleadores, consagraba tanto el derecho del trabajador sobre sus invenciones como la posibilidad de que contractualmente se cediera dicha titularidad, con la novedad de que se establecía la nulidad de aquellas cláusulas que negaran al inventor un beneficio económico razonable en virtud de su invención. Véase Lema Devesa, Carlos (1990). "Las invenciones laborales en la Ley de Patentes de 20 de marzo de 1986". En Bisval, J. y Viladás, C. (coordinadores). Derecho y Tecnología: Curso sobre innovación y transferencia. Barcelona: Ariel, pp. 145-156, p. 146; y LoIs (2000) 37-38. 
En nuestro país, la Propiedad Industrial es una materia que se reguló desde los comienzos de la República ${ }^{12}$. Sin embargo, las invenciones de los trabajadores fueron tratadas por primera vez con la dictación de la Ley 19.039, de Propiedad Industrial, la cual contempló un estatuto para las creaciones de los trabajadores-inventores. Actualmente esta clase de invenciones se encuentran reguladas en el Título VI de dicho cuerpo legal, denominado "De las invenciones en servicio"13, que reconoce tres categorías ${ }^{14}$, las que denominaremos en este trabajo como invenciones contratadas o por encargo (arts. 68 y 69 inc. $3^{\circ} \mathrm{LPI}$ ); invenciones mixtas o de explotación (art. 69 inc. $2^{\circ} \mathrm{LPI}$ ); e invenciones pertenecientes al trabajador o libres (art. 68 inc. $\left.1^{\circ} \mathrm{LPI}\right)^{15}$.

\section{2) LA TITULARIDAD EN LAS INVENCIONES EN SERVICIO}

El legislador chileno, siguiendo a la doctrina y legislación compara$\mathrm{da}$, ha establecido una clasificación tripartita de las distintas formas de invenciones laborales. Esta clasificación tiene como finalidad esencial determinar la atribución del derecho a la patente así como los derechos secundarios que, en su caso, puedan corresponder a quien no la obtenga ${ }^{16}$.

12 Pueden citarse en este sentido el Decreto Ley de 9 de septiembre de 1840, el Decreto Ley $\mathrm{N}^{\circ} 588$, de 3 de noviembre de 1925, y el Decreto con Fuerza de Ley No 291 de 1931 y sus sucesivas modificaciones.

13 Nos parece que el ámbito de aplicación del Título VI de la LPI comprende, en principio, a todos los derechos de protección exclusiva reconocidos en dicha ley; se abarcarían, entonces, además de las patentes de invención (arts. 31 ss LPI), los modelos de utilidad (arts. 54 ss LPI), los esquemas de trazados o topografías de circuitos integrados (art. 73 ss LPI) y los dibujos y diseños industriales (arts. 62 ss. LPI) (véase Sierra Herrero, Alfredo (2005). "Ingenio y trabajo. Las invenciones laborales en el Derecho español y chileno". Revista de Derecho de la Universidad Católica del Norte, año $12 \mathrm{~N}^{\circ} 1$, pp. 121-155, pp. 151-152). Surge la duda sobre la posibilidad de aplicar analógicamente la regulación de las invenciones en servicio a otros títulos de propiedad exclusiva no contenidos en la LPI, como p. ej. en materia de creaciones vegetales, reguladas por la Ley $\mathrm{N}^{\circ}$ 19.342. A este respecto, nos parece que teniendo en cuenta las normas del Título VI de la LPI (en especial el art. 71), en principio no sería posible sostener una aplicación extensiva de las disposiciones de estas invenciones a otros títulos de propiedad exclusiva no contenidos en la LPI. Con todo, lo recomendable sería que en cada ley especial referida a algún título de propiedad exclusiva se señale expresamente si las normas del Título VI de la LPI serán o no aplicables.

14 Esta división tripartita, sin perjuicio de las particularidades que posteriormente analizaremos, es la que se ha utilizado en la doctrina comparada desde el Congreso de Augsburgo de la Asociación alemana para la Propiedad Industrial del año 1914. En este sentido, véase Guisado, Héctor (2010). "Capítulo IV. Desarrollo de la relación. A) Derechos y deberes de las partes". En Rodríguez Mancini, Jorge (director). Derecho del trabajo. Buenos Aires: Astrea, T. I, pp. 425-494, p. 433-434; y LoIs (2000) p. 37).

15 Sobre las distintas denominaciones que la doctrina comparada concede a estas clases de invenciones, véase en detalle LOIS (2000) 120 ss.

16 Véase Lois (2000) 117. 


\section{(2.1) LAS INVENCIONES CONTRATADAS O POR ENCARGO}

\section{(2.1.1) Aspectos generales}

Se encuentran reguladas en el art. 68 de la LPI, según el cual "En los contratos de trabajo y prestación de servicios, cuya naturaleza sea el cumplimiento de una actividad inventiva o creativa, la facultad de solicitar el registro así como los eventuales derechos de propiedad industrial, pertenecerán exclusivamente al empleador o a quien encargó el servicio, salvo estipulación expresa en contrario"17. Como se aprecia, la titularidad de estos inventos se otorga directamente al empleador, no obstante las partes pueden modificar dicha titularidad en orden a que ella corresponda, en todo o parte, al trabajador ${ }^{18}$.

La doctrina las ha definido como aquellas invenciones pertenecientes al empleador, que se vale de sus trabajadores para desarrollarlas ${ }^{19}$. Su atribución al empresario es una materia donde ha existido general acuerdo en la doctrina comercial y laboral comparada ${ }^{20}$, pues se considera que ella es la consecuencia normal de la identificación entre invención y prestación contractualmente debida al empleador ${ }^{21}$. Se dice que es la aplicación de la

17 Es destacable que esta norma comprenda expresamente tanto los "contratos de trabajo" como los de "prestación de servicios", no utilizándose el término "trabajador" y señalándose que tanto la facultad de solicitar el privilegio como los eventuales derechos de propiedad industrial pertenecerán al "empleador" o a "quien encargó el servicio". Para un análisis acerca de la inclusión de supuestos distintos a los contratos de trabajo en esta clase de invenciones, véase SierRa (2005) 145-146.

18 Véase Sierra (2005) 148; y Sierra Herrero, Alfredo (2010). "Invenciones de los trabajadores a la luz de la ley de propiedad industrial”. Revista de Derecho de la Empresa, No 24, pp. 73-82, p. 77, donde se destaca que este pacto en contrario puede estipularse tanto en el contrato de trabajo como en un instrumento posterior.

19 Véase Estupiñán (2003) 178.

20 La titularidad otorgada al empleador, sin embargo, solo alcanzará a los derechos patrimoniales derivados de la invención, no al denominado derecho moral del inventor, que ha sido definido por la doctrina comparada como aquel "derecho del inventor a ser reconocido públicamente como tal con independencia de la persona que solicite -y obtenga- la patente sobre el invento en cuestión" (Illesscas Ortiz, Rafael (2010). "Lección 7ª . El Derecho industrial y el régimen jurídico de la competencia”. En JimÉnez SÁnchez, Guillermo (coordinador). Lecciones de Derecho Mercantil. 14 $4^{\mathrm{a}}$ Ed. Madrid: Tecnos, pp. 126-149, p. 128). Como acertadamente se ha seńalado en la doctrina espańola, se trata de un derecho personalísimo, inalienable, inembargable e intransferible; a su vez, aunque no tiene carácter patrimonial directo, su violación puede dar lugar a reparación pecuniaria, de acuerdo a las normas generales sobre responsabilidad civil (Estupiñán (2003) 182). Sin perjuicio de las referencias comparadas antes señaladas, lo cierto es que la LPI no se refiere expresamente al derecho moral del inventor, como sí lo hace la Ley No 17.336, de Propiedad Intelectual, respecto a los autores de creaciones cubiertas por dicha ley (arts. 14 ss Ley No 17.336). Una referencia implícita a él en materia de Propiedad Industrial parece ser la del artículo 11 letra b) del Reglamento de la LPI (Decreto Supremo N²36/Min. Economía), que exige que en la respectiva solicitud de patente de invención o modelo de utilidad se deba incluir el nombre completo, nacionalidad y domicilio del inventor.

21 Véase, en el Derecho español, Martín, Antonio et al. (2006). Derecho del Trabajo. 15a Ed. 
regla fundamental del Derecho del Trabajo, en virtud de la cual los productos de la actividad del trabajador dependiente pertenecen al empresario $^{22}$. A su vez, se ha señalado que es lógico el proceder de la ley en defensa del empresario, ya que este no solo deberá invertir en el desarrollo de la investigación, sino también en su industrialización ${ }^{23}$ y comercialización (p. ej. inversión previa para conocer las tendencias del mercado, establecimiento y puesta en marcha de una red de comercialización, etc. $)^{24}$.

La elección del legislador nacional en esta materia supone la aceptación de la tesis de la adquisición directa de la invención por parte del empleador, sin que se requiera un acto dispositivo posterior del trabajador ${ }^{25}$. Sin embargo, en la práctica muchas veces se efectúa la cesión de derechos del trabajador al empleador, dado que el art. 11 del Reglamento de la LPI (Decreto Supremo $N^{\circ}$ 236/Min. Economía) establece que si el solicitante de la patente es diferente del inventor se debe acompañar tal cesión debidamente legalizada (art. 11). Con todo, nos parece que esta disposición del Reglamento no considera el supuesto de la invención contratada (que

Madrid: Tecnos, 959 pp., pp. 644-645; Diéguez Cuervo, Gonzalo (1995). Lecciones de Derecho del Trabajo. 4a Ed. Madrid: Marcial Pons, 790 pp., p. 242; Alonso (1987) 87 ss; y Lema (1990) 150. En el Derecho francés, Gridel (1980) 58. En el Derecho italiano, Sena, Giuseppe (1990). I diritti sulle invenzioni e sui modelli industriali. $3^{a}$ Ed. Milán: Giuffrè, 674 pp., pp. 152 ss. En el Derecho norteamericano, SAvitsky, Thomas (1991). "Compensation for employee inventions". Journal of the Patent Office Society, N 73, pp. 646 ss.

22 Véase Lois (2000) 157; y Luque Parra, Manuel (2005). "La (re)definición del concepto de "trabajador" en el ámbito de las nuevas tecnologías a la luz del derecho de propiedad industrial y de propiedad intelectual”, en Del Rey Guanter, S. (director) y Luque Parra, M. (coordinador). Relaciones Laborales y Nuevas Tecnologías. Madrid: La Ley, pp. 77-104, pp. 88 ss. Como apuntan Alonso Olea y Casas BaAmonde, en el ámbito laboral los frutos del trabajo son atribuidos inicial y directamente a persona distinta de quien ha ejecutado el trabajo. La atribución ocurre en virtud de una singular relación entre el trabajador y el adquirente de los frutos, la relación de ajenidad (véase Alonso Olea, Manuel y Casas BaAmonde, María Emilia (2006). Derecho del Trabajo. 24a Ed. Madrid: Civitas, 1.289 pp., p. 56).

23 Véase García Díaz, Margarita, e Hidalgo Rúa, Gloria (1996). "Invenciones y creaciones intelectuales: especial referencia al software". Acciones e investigación sociales, $\mathrm{N}^{\circ} 4$, pp. 81 91, p. 84. En el mismo sentido, Bernhardt, Wolfgang y Krasser, Rudolf (1986). Lehrbuch des Patentrechts. $4^{a}$ Ed. Munich: Beck, 741 pp., p. 244; y Hershovitz, Marc (1995). "Unhitching the trailer clause: The rights of inventive employees and their employers". Journal of Intellectual Property Law, $\mathrm{N}^{\circ}$ 3, pp. 187-212, p. 191.

24 Véase Merges, Robert (1999). "The Law and Economics of Employee Inventions". Harvard Journal of Law \& Technology, Vol. 13, $\mathrm{N}^{\circ} 1$, pp. 1-54, p. 31. Como destaca este autor, la "investigación y desarrollo" (I+D) es un área altamente problemática, pues no existe certeza que de ella se logre efectivamente una invención, que sea patentable, ni menos aun que su explotación sea económicamente viable. La regulación legal, entonces, debe proteger de alguna forma al empleador que afronta todos estos riesgos, ya sea otorgándole la titularidad de los derechos patrimoniales o, al menos, concediéndole un derecho preferente de utilización de la invención patentada por su trabajador. La crítica a la atribución de la titularidad al empleador, señala el autor citado, solo surge en el momento en que la invención es alcanzada, es decir, cuando la incertidumbre de la actividad deja de existir, y se vislumbran con mayor claridad sus futuros beneficios. 
es una excepción legal al principio de Propiedad industrial referido a que el inventor es el titular de la patente), donde la ley le atribuye ab initio la titularidad de la patente a la empresa. Es por eso que esta tiene derecho a solicitar el privilegio industrial, sin que medie cesión alguna del trabajador.

La distinción entre la titularidad originaria del trabajador y la obligatoriedad de la respectiva cesión al empleador se encuentra más claramente en el Derecho alemán, pues su Ley sobre Invenciones de los Trabajadores (Gesetz über Arbeitnehmererfindungen o ArbnErfG) dispone que el empleador "podrá" reclamar la titularidad de la invención (lo que dicha ley denomina reclamación "sin restricciones"), caso en el cual se le transferirán todos los derechos de la invención en servicio $(\$ 7 \text { (1) ArbnEfrG })^{26}$.

De todas formas, si bien coincidimos en que se atribuya la titularidad de esta clase de invenciones al empleador, creemos que nuestra ley debiera contemplar un plazo para solicitar el privilegio, luego del cual, si no se ejerce dicha facultad, esta correspondería al inventor o equipo de inventores que la llevaron a efecto ${ }^{27}$. Reconocemos, sin embargo, la dificultad práctica de fijar una regulación en tal sentido, pero consideramos que con ello el objetivo primordial que el legislador ha buscado al regular las invenciones en servicio, cual es el desarrollo técnico, se encontraría mejor protegido. Como bien ha señalado Estupiñán Cáceres en el Derecho español, atribuir al empresario incondicionalmente la titularidad de estas invenciones, sin tomar lo anterior en consideración, "no protege adecuadamente los intereses del conjunto de la sociedad, ni los de los trabajadores en particular" 28 .

26 La situación es distinta en el Derecho español, en que el artículo 15.1 de su Ley de Patentes dispone que "Las invenciones realizadas por el trabajador durante la vigencia de su contrato o relación de trabajo o de servicios con la empresa, que sean fruto de una actividad de investigación explícita o implícitamente constitutiva del objeto de su contrato, pertenecen al empresario". De acuerdo a la doctrina española mayoritaria, esta disposición da cuenta de la titularidad originaria del empleador de esta clase de invenciones (véase, por todos, RodRíguez-Piñero y Bravo-Ferrer, Miguel (1986). "El nuevo régimen jurídico de las invenciones laborales". Relaciones Laborales, Nº 6, pp. 41-48, p. 46; y Feas Costilla, Javier (1987). "Las invenciones laborales en la ley de patentes de 1986". Revista del Trabajo, No 87, pp. 121-136, p. 128. En el mismo sentido, desde la antigua regulación espańola, Albiol (1975) 113). A una conclusión similar llega la doctrina argentina (véase Guisado (2010) 433).

27 Una acertada solución a este problema se encuentra en el Derecho alemán. De acuerdo al $\$$ 6 de la ArbnEfrG, la reclamación de la titularidad de la invención por parte del empleador debe realizarse tan pronto como sea posible, existiendo como plazo máximo cuatro meses desde que el trabajador le informó de ella a su empleador (conforme al $\$ 5$ de la ArbnEfrG, el trabajador que realice una invención en servicio tiene la obligación de informárselo). Si no se reclama dicha titularidad en el plazo antes señalado, la invención se vuelve "libre" y el trabajador puede solicitar la respectiva patente ( $\$ 8$ (3) ArbnEfrG). Lo anterior es sin perjuicio que se reconoce al empleador la posibilidad de no hacer pública la invención cuando exista un interés legítimo de mantenerla como secreto industrial, debiendo en tales casos cumplir ciertos requisitos adicionales establecidos en la ley ( $\$ 17$ ArbnEfrG).

28 Estupiñán (2003) 187. A juicio de esta autora, ello se debe a que este esquema permitiría al empleador mantener las invenciones en secreto o no explotarlas. 


\section{(2.1.2) Objeto del contrato}

Según se deduce del art. 68 de la LPI, el objeto del contrato por parte del trabajador no consiste en obtener un resultado - una invención-, sino el desarrollo de una actividad inventiva. Se dispone así que la naturaleza de esta clase de contratos es "el cumplimiento de una actividad inventiva o creativa” (art. 68 LPI). A este respecto, Gómez Segade ha señalado que argumentar lo contrario "sería simplemente absurdo, porque la investigación está dirigida hacia lo desconocido, y no pueden garantizarse resultados

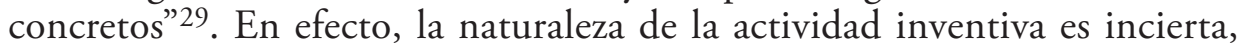
y no existe seguridad de que una idea llegue a convertirse en una invención, ni menos que, aunque esta se alcance, llegue a ser patentada ${ }^{30}$.

En cuanto al objeto de estos contratos surge el problema relativo al grado de determinación que este debe presentar ${ }^{31}$. En especial, si son válidas las cláusulas que contemplen misiones inventivas muy genéricas, que puedan abarcar cualquier invención del trabajador -sea o no parte de su actividad laboral inventiva-, y que, en definitiva, impliquen que su titularidad pertenezca al empleador.

Sobre la determinación de la obligación que corresponde al trabajador, el art. $10 \mathrm{~N}^{\circ} 3$ del CdT dispone que "El contrato de trabajo debe contener, a lo menos, las siguientes estipulaciones: (...) 3.- determinación de la naturaleza de los servicios y del lugar o ciudad en que hayan de prestarse. El contrato podrá señalar dos o más funciones específicas, sean estas alternativas o complementarias'"32.

Nuestra doctrina laboral ha manifestado que "la determinación de la naturaleza de los servicios implica que se consigne el cargo específico o

29 Gómez (1984) 120-121.

30 Véase Lema (1990) 150. Analizando el artículo 15.1 de la Ley de Patentes española, similar en esta materia al artículo 68 de la LPI, este autor señala que "cuando hablamos de misión inventiva nos referimos, evidentemente, a la misión de investigación. Porque, acertadamente, la ley habla de actividad de investigación, ya que el objeto del contrato no es inventar. El objeto será la investigación, con independencia de que la misma conduzca o no a una invención".

31 Brevemente cabe recordar que el objeto como requisito de validez común a todo contrato, se encuentra establecido en el art. 1460 del Código Civil, según el cual "toda declaración de voluntad debe tener por objeto una o más cosas que se trata de dar, hacer o no hacer". Como la prestación laboral constituye una obligación de hacer, su objeto debe ser determinado, lícito, así como física y moralmente posible (véase León Hurtado, Avelino (1983). El Objeto en los Actos Jurídicos. 2a Ed. Santiago: Editorial Jurídica de Chile, 151 pp., pp. 25 ss). En lo que nos interesa, se ha entendido que el fundamento del requisito de determinación surge "de la propia naturaleza de las cosas, ya que debe conocerse específicamente en qué consiste el hecho o la abstención objeto de la obligación. Es decir, el deudor debe saber qué debe y el acreedor qué puede exigir" (LeÓN (1983) 26).

32 Véase Lanata Fuenzalida, Gabriela (2006). Contrato individual de trabajo. $3^{\text {a }}$ Ed. Santiago: LexisNexis, 318 pp., p. 111, para quien "esta es una de las estipulaciones más importantes del contrato de trabajo, pues dice relación con la obligación principal del trabajador, que es precisamente la de prestar servicios a favor del empleador". 
función que el trabajador se obliga a desempeñar, para evitar que el empleador arbitrariamente altere las condiciones en que el trabajador debe prestar sus servicios 'por la vía de cláusulas amplias o indeterminadas"'33. La doctrina comparada, por su parte, ha destacado que el requisito de "determinación" cumple dos finalidades; por un lado, garantiza la seriedad de las obligaciones contraídas, tutelando en consecuencia un interés general; y, por el otro, protege a una de las partes del contrato de la imposición arbitraria de la prestación debida por parte de la otra, tutelando así un interés individual ${ }^{34}$. Se afirma que se trata de una cuestión de "interés cualificado" para el trabajador, pues "solo desde ella (se) podrá limitar el margen de arbitrariedad que los hechos vienen a conceder a su acreedor" 35 .

Los tribunales de justicia, en tanto, han señalado que las "funciones específicas a desarrollar por parte del trabajador, deben ser consignadas en el contrato respectivo, pues ellas son la razón que lleva al empleador a suscribir dicha convención e implican, a su vez, la delimitación del ámbito dentro del cual este ejercerá la dirección sobre aquel"36; considerándose que la excesiva "amplitud o falta de delimitación de tareas" puede incluso significar un detrimento para el trabajador ${ }^{37}$. En este sentido, se ha subrayado la importancia de la determinación de funciones, en materias de la procedencia de despidos - a propósito de la calificación de un incumplimiento grave de obligaciones contractuales (art. $160 \mathrm{~N}^{\circ} 7 \mathrm{CdT}$ )_38, de despidos indirectos (art. $171 \mathrm{CdT})^{39}$, y en la aplicación del ius variandi $(\text { art. } 12 \mathrm{CdT})^{40}$. Por su parte, la Dirección del Trabajo ha indicado que es necesario conocer con exactitud y sin lugar a dudas la labor o servicio que el dependiente se obliga a ejecutar para el respectivo empleador, lo cual obedece a "la intención del legislador de que el dependiente conozca con certeza el o los servicios que deberá prestar, en términos que se evite que en este aspecto quede sujeto al arbitrio del empleador" ${ }^{41}$.

33 Gamonal Contreras, Sergio y Guidi Moggia, Caterina (2010). Manual del Contrato de Trabajo, Santiago: AbeledoPerrot-LegalPublishing, 342 pp., p. 75. En el mismo sentido, Lizama Portal, Luis (2003). Curso de Derecho del Trabajo. Santiago: LexisNexis, 238 pp., p. 40.

34 Véase Cuenca Alarcón, Miguel (2006). La determinación de la prestación de trabajo. Madrid: CES, 379 pp., p. 39.

35 Cuenca (2006) 63.

36 Corte Suprema, sentencia de 20 de diciembre de 2006, Rol 790-2005. Disponible en jurisprudencia on line de LegalPublishing.

37 Véase Corte Suprema, sentencia de 20 de diciembre de 2006, Rol 790-2005. Disponible en jurisprudencia on line de LegalPublishing.

38 Véase Corte de Santiago, sentencia de 3 de septiembre de 2002, Rol 7069-2001. Disponible en jurisprudencia on line de LegalPublishing.

39 Véase Corte Suprema, sentencia de 20 de diciembre de 2006, Rol 790-2005. Disponible en jurisprudencia on line de LegalPublishing.

40 Véase Corte de Punta Arenas, sentencia de 10 de diciembre de 2010, Rol 45-2010. Disponible en jurisprudencia on line de LegalPublishing.

41 Dirección del Trabajo, Dictamen Ord. N 4058/202, 3 de julio de 1995. 
La amplitud de las cláusulas que contemplan quehaceres inventivos, es un tema que se ha desarrollado por la doctrina comparada a propósito del análisis de la eficacia de las llamadas "cláusulas de estilo" 42 . A través de ellas se fijan misiones generales de investigación, en virtud de las cuales se pretende que el empleador sea titular de todas las invenciones realizadas por el trabajador-inventor, sea que estén o no relacionadas con la prestación que realiza ${ }^{43}$.

A nuestro entender, la importancia de determinar la misión inventiva reside en buena medida en evitar que, a través de una cláusula excesivamente general, la empresa termine siendo titular de las invenciones conocidas como "libres"; es decir, aquellas que son realizadas por un trabajador que no está contratado para realizar una actividad de investigación (art. 69 inc. $1^{\circ}$ LPI). Previamente corresponde hacer una aclaración, y es que si bien dicha norma se refiere en principio al trabajador que no se encuentra "obligado a realizar una actividad inventiva o creativa”, debiera también entenderse comprendido en ella a aquel trabajador que realiza una invención -libre- originada en una investigación que no es parte de la misión inventiva estipulada en el contrato. De no ser así, bastaría con que el contrato de trabajo contemplara dentro de su objetivo cualquier actividad inventiva, para que toda invención del trabajador, aunque sea ajena al contenido de dicho contrato, no se considere como libre. Por esto decimos que la invención libre puede ser, o bien aquella realizada por un trabajador que no está obligado a desarrollar tareas de investigación, o bien aquella que consigue un trabajador que sí está contratado para realizar dichas tareas, pero que llevó a cabo - por su cuenta- otras investigaciones que no coinciden con las contratadas.

En este contexto, las cláusulas que contemplen actividades inventivas muy amplias pueden llegar a significar que el derecho de los trabajadores a obtener sus propias invenciones pueda resultar inoperante. Para examinar la eficacia de estas cláusulas en cuanto a su amplitud, creemos que un factor clave consiste en la función real que desempeñe el trabajador ${ }^{44}$ (recuérdese la importancia que se otorga en nuestro ámbito laboral a la aplicación práctica que las partes efectúan del contrato a la hora de de-

\footnotetext{
Véase LoIs (2000) 134.

LoIs (2000) 134.

Una interesante aproximación a la determinación de las funciones efectivamente debidas por el trabajador se encuentra en el Derecho argentino. Como ha destacado su doctrina, interpretando el artículo 37 de su Ley de Contrato de Trabajo, el contenido del contrato de trabajo está determinado por la calificación de la o las tareas que las partes acordaron como constitutivas de la relación laboral, y no por la calificación profesional del trabajador. Véase Armando Grisolía, Julio (2008). Manual de Derecho Laboral. 4a Ed. Buenos Aires: LexisNexis, 1.053 pp., p. 95.
} 
terminar el alcance de sus cláusulas ${ }^{45}$ ). Así las cosas, aquella cláusula que comprenda más tareas inventivas que aquellas realizadas efectivamente podría estimarse que afecta a las invenciones que el trabajador lleve a cabo por su cuenta, y de esa forma ir en contra de un derecho irrenunciable ${ }^{46}$.

En efecto, esta situación sería contraria a lo dispuesto en el art. 71 LPI, que prescribe la irrenunciabilidad anticipada de los derechos de los trabajadores referidos a las invenciones en servicio ${ }^{47}$. $Y$ es que, en definitiva, por medio de dichas cláusulas los trabajadores estarían renunciando a ser titulares de aquellas invenciones que les pertenecen por ley. De este modo, si una cláusula conlleva tal infracción debiera tenerse "por no escrita” en todo o parte, según lo dispone el artículo en comento.

\section{(2.2.) LAS INVENCIONES MIXTAS (ART. 69 INC. $2^{\circ}$ LPI)}

\section{(2.2.1) Aspectos generales}

El inc. $1^{\circ}$ del art. 69 de la LPI hace referencia a las invenciones pertenecientes en forma exclusiva a los trabajadores, conocidas normalmente en doctrina como invenciones libres. Ellas consisten en invenciones

45 Como afirma Gamonal, en materia de contratos consensuales, como el contracto de trabajo, se acepta su modificación tácita, que se manifiesta a través de la aplicación práctica que las partes han efectuado de sus cláusulas. Afirma el autor, que "los hechos revelan la voluntad real de los contratantes, ya que si el contrato se cumple de determinada manera es porque las partes consienten en ello". Gamonal Contreras, Sergio (2008). Fundamentos de Derecho Laboral. Santiago: LegalPublishing, 168 pp., p. 121. Como se sabe, esta clase de modificaciones reciben la denominación de "cláusulas tácitas". (véase Melis VAlencia, Christian (1997). "Cláusulas tácitas". Boletin Oficial de la Dirección del Trabajo, N 103, pp. 1-13, p. 3; las que se consideran como una materialización del Principio de Primacía de la Realidad (Gamonal (2008) 121. Véase también Melis (1997) 3). Sobre la procedencia de las cláusulas tácitas, parte de la doctrina nacional -con la cual coincidimos- sostiene que estas no pueden operar si significan una "infracción reiterada por parte de un empleador de alguna de sus obligaciones contractuales (...) dado que ello normalmente no obedecerá a un consentimiento tácito del trabajador, sino a su situación de desmedro frente al empleador" (Lanata (2006) 118; y GamonaL/Guidi (2010) 82). Por su parte, Rojas se plantea si dichas cláusulas pueden operar no solo a favor sino también en su contra y sobre ello concluye que "de acuerdo a los principios generales del Derecho del Trabajo no es aceptable tal posibilidad, toda vez que estando vigente una relación laboral en muchos casos sería difícil o imposible para el trabajador alegar el respeto de la cláusula inicial y, de esta manera, significaría una imposición de una modificación unilateral del empleador" (RoJas Miño, Irene (2004). Manual de Derecho del Trabajo. Santiago: LexisNexis, 309 pp., p. 42).

46 En este sentido, en ordenamientos comparados como el francés se exige expresamente que la misión inventiva encomendada al trabajador "corresponda a sus funciones efectivas" (véase LoIs (2000) 134).

47 Nos parece que en estos casos estaríamos en presencia de un fraude de ley. Así, por lo demás, lo reconocen autores como Muosseron, que considera la atribución sistemática e indiferenciada de misiones de investigación muy amplias en los contratos de trabajo, podría ser sospechosa de "fraude a la ley", en tanto ellas llevarían a que todas las invenciones obtenidas por los trabajadores pertenezcan al empleador (Muosseron, Jean Marc (1984). Traité des Brevets. París: CEIPI, Vol. I, 1.097 pp., p. 521). Sobre el fraude a la ley en la doctrina nacional, véase León (1983) 31 ss; y Gamonal (2008) 123. 
obtenidas por un dependiente que, según su contrato de trabajo, no se encuentra obligado a realizar una función inventiva o creativa. Con todo, la LPI concede en ciertos casos la titularidad a la empresa de las invenciones efectuadas por trabajadores, a pesar de que no hayan sido contratados para desarrollar funciones de naturaleza inventiva. Para que ello suceda se exige que el trabajador "se hubiera beneficiado de modo evidente de los conocimientos adquiridos dentro de la empresa y utilizara medios proporcionados por esta" (art. 69 inc. $2^{\circ}$ LPI). Estas invenciones reciben, según ya adelantamos, la denominación de mixtas o de explotación ${ }^{48}$.

Como se ha destacado en el Derecho comparado, esta clase de invenciones en servicio constituye una categoría intermedia entre las denominadas contratadas o por encargo (art. $68 \mathrm{LPI}$ ) y las libres (art. 69 inc. $^{\circ}$ LPI), ya que a pesar que el trabajador no ha sido contratado para realizar una actividad de investigación, ha desarrollado una invención en cuya consecución resultaron clave las condiciones ("conocimientos y medios") que la empresa ha puesto a su disposición para prestar sus servicios, y de ahí que se le concede a esta su titularidad ${ }^{49}$.

\section{(2.2.2) Requisitos de las invenciones mixtas}

En general dos son los requisitos que deben concurrir para que nos encontremos ante esta clase de invenciones, a saber: a) que el trabajador no haya sido contratado para realizar actividades inventivas o creativas; y b) que el trabajador se haya beneficiado de los medios y conocimientos proporcionados por la empresa para conseguir la invención.

(a) No haber sido contratado para realizar actividades inventivas

Se trata de un requisito negativo -como bien lo ha destacado un sector de la doctrina comparada ${ }^{50}$-, toda vez que la invención no puede ser el resultado de una actividad investigativa pactada. De esta suerte, el resultado obtenido por el trabajador -la invención- debe ser de carácter extraordinario, en tanto no forma parte de la obligación debida ${ }^{51}$; característica fundamental que diferencia esta clase de invención de la denominada contratada o por encargo ${ }^{52}$.

\footnotetext{
48 Véase, en este sentido, Blanco Jiménez, Araceli (1999). Protección jurídica de las invenciones universitarias y laborales. Pamplona: Arazandi, 345 pp., pp. 103 ss; FeAs (1987) 129; y Pérez PéRez, Manuel (1994). Invenciones laborales de trabajadores, profesores universitarios y personal investigador. Madrid: Civitas, 397 pp., pp. 161 ss

49 Véase Lois Bastida, Fátima (1999a). "La atribución de los resultados de la investigación contratada en la Ley de Patentes". Anuario da Facultade de Dereito da Universidade da Coru$\tilde{n} a, \mathrm{~N}^{\circ} 3$, pp. 331-349, p. 335.

50 Véase, por todos, Estupiñ́n (2003) 196; Lois (2000) 138-139; y Lema (1990) 150.

51 BLANCO (1999) 103

52 Blanco (1999) 103.
} 
Pérez señala que esta invención no será una consecuencia de una actividad obligada, sino fruto, bien de la casualidad, bien de la propia iniciativa ${ }^{53}$. Por su parte, Lois Bastida apunta que, mientras en las invenciones contratadas o por encargo existe una relación de causalidad entre actividad debida y la invención, en las invenciones mixtas existe una relación de conexión entre el resultado inventivo y la actividad realizada por el trabajador en el ejercicio de sus funciones ordinarias ${ }^{54}$. En efecto, el trabajador logrará normalmente esta clase de invención como consecuencia del desarrollo dichas funciones. Sobre todo, en aquellos casos en los que el objeto del contrato se refiere a actividades (no investigativas) potencialmente idóneas para conseguir un resultado inventivo; tal sería el ejemplo -como lo ilustra Blanco Jiménez- del invento de un técnico comercial -cuyo contrato no prevea el desarrollo de actividades de investigación- conseguido gracias a las diversas sugerencias recibidas de parte de los clientes que debe atender ${ }^{55}$.

\section{(b) Conocimientos y medios de la empresa}

Se requiere, a su vez, que el inventor se hubiera beneficiado de manera evidente de los conocimientos adquiridos dentro de la empresa y que, además, haya utilizado medios proporcionados por esta (art. 69 inc. $2^{\circ}$ LPI). Como se advierte, es necesaria la presencia de dos elementos: los conocimientos y los medios facilitados por la empresa. Ambos deben concurrir en forma simultánea en la consecución de la invención. Se destacó así durante la tramitación de la LPI en la Comisión de Economía, Fomento y Desarrollo de la H. Cámara de Diputados, por el H. Diputado Francisco Bayo: “(...) los conocimientos adquiridos dentro de la empresa y la propiedad de los medios utilizados para la invención deben ser requisitos copulativos y no alternativos, para que el derecho a la invención pertenezca al empleador" 56 . Por consiguiente, si falta uno de ellos, la invención no podría ser calificada como "mixta", sino más bien como "libre". Recordemos que la invención mixta debe entenderse como una excepción a

PÉReZ (1994) 164-165.

LoIs (2000) 121.

BLANCO (1999) 103.

Biblioteca del Congreso Nacional (1991). Historia de la Ley No 19.039. Disponible en línea: http://www.bcn.cl/obtienearchivo?id=recursoslegales/10221.3/12821/5/HL19039.pdf [consultado el 19 de julio de 2011], 452 pp., pp. 103-104. La indicación citada forma parte del Segundo Informe de la Comisión de Economía, Fomento y Desarrollo de la H. Cámara de Diputados. Esta situación, aunque se deduce del texto legal y era reconocida por nuestra doctrina (véase García-Huidobro Amunátegui, Vladimir (1992). Legislación sobre propiedad industrial. Análisis, jurisprudencia y guia práctica. Santiago: Editorial Jurídica de Chile, 279 pp., p. 174), fue tratada de forma errónea por el artículo 112 del anterior Reglamento de la LPI (Decreto Supremo No 177/Min. Economía, de 6 de mayo de 1991, hoy derogado), que los presentaba como alternativos (véase Sierra (2005) 148-149). 
la titularidad de la invención por parte del trabajador no contratado para investigar, en tanto se acredite el cumplimiento de los requisitos legales que la hacen procedente ${ }^{57}$.

Parece ser que esta exigencia de concurrencia simultánea es una particularidad de nuestra legislación nacional, frente a lo que sucede en el Derecho comparado. En efecto, en ordenamientos como el argentino y el espańol que, en esta materia poseen una estructura normativa similar a la nuestra, la presencia de dichos elementos se requiere solo en forma alternativa, siendo así suficiente que se cumpla simplemente con uno de ellos para encontrarnos ante una invención de esta clase ${ }^{58}$.

Centrándonos en el examen de estos elementos, comenzando por los "conocimientos", es posible apuntar, como primera cuestión, que se trata de un aporte de orden inmaterial, ya que por "conocer" se entiende la acción de "averiguar por el ejercicio de las facultades intelectuales la naturaleza, cualidades y relaciones de las cosas" 59 . La clave se encuentra en un "averiguar" que obviamente conlleva un ejercicio "intelectual"; luego, para el tema que nos importa, el conocimiento adquirido por el trabajador-inventor -a través de ese "averiguar"- se logró gracias a las condiciones que la empresa puso a su disposición para la prestación de sus servicios. Se señala que estas condiciones pueden consistir en "informaciones, know-how, prácticas, ideas obtenidas de conversaciones con colegas, distribuidores o cooperadores y, en definitiva, cualquier contribución inmaterial de estímulo intelectual nacida de reflexiones de un espíritu individual y crítico" 60 .

De esta manera, estos conocimientos se pueden adquirir de la propia experiencia que genera el cargo en su desarrollo, como también de las

57 Véase, en el Derecho español, Álvarez Montero, Antonio (2008). "Invenciones laborales. Un marco jurídico viejo para un nivel de investigación creciente”. Trabajo: Revista andaluza de relaciones laborales, $\mathrm{N}^{\circ} 21$. pp. 141-166, p. 153.

58 En el Derecho español se trata de requisitos alternativos, según dispone el artículo 17.1 de la Ley de Patentes espańola. Similar es el caso del Derecho argentino, según dispone el artículo 10 letra b) de su Ley $\mathrm{N}^{\circ}$ 24.481, de Patentes de Invención y Modelos de Utilidad. En el Derecho alemán, aunque no se trata de conceptos idénticos a los utilizados por el legislador nacional, sus requisitos también se presentan como alternativos ("experiencia" o "actividades" de la empresa), según dispone el $\$ 4$ (2) letra b) de la ArbnEfrG (véase Reitzle, Helmut et al. (2007). German Act on Employees' Inventions. Munich: Verlach C.H. Beck, 112 pp., p. 5).

59 Real Academia Española (2001). Diccionario de la Lengua Española. 22a Ed. Disponible en línea: http://buscon.rae.es/draeI/SrvltConsulta?TIPO_BUS=3\&LEMA=conocer [consultado el 27 de junio de 2011].

60 Lois (2000) 145. En el mismo sentido, Pérez (1994) 165-166, para quien "por 'conocimientos' hay que entender ejercicios, habilidades técnicas, el know-how, y el savoir faire que se aplican con regularidad en la empresa así como ideas, hipótesis de trabajo e investigaciones en curso o, incluso, la contribución inmaterial de impulso y estímulo intelectual, nacidos de un espíritu observador y curioso o de conversaciones con otros trabajadores de la empresa, o sea, todo lo que puede caer en el ámbito del potencial intelectual de la empresa respecto de los cuales el trabajador se ha comportado de manera parasitaria". 
etapas previas de formación -si las ha habido-, en una fase de adaptación o readaptación profesional e, incluso, en los casos en que el trabajador haya tenido acceso a ellos sin mediar acuerdo previo con su empleador ${ }^{61}$. En este sentido, las funciones que el trabajador desempeña al interior de la empresa deberán -precisamente- constituir la ocasión para que este adquiera los conocimientos técnicos, que serán el elemento decisivo a la hora de la obtención de la invención ${ }^{62}$.

Subrayamos el carácter decisivo de estos conocimientos -adquiridos en la empresa- a la hora de conseguir la invención, ya que la LPI exige que el trabajador se haya beneficiado "de modo evidente" de estos en la consecución de ese resultado. Es decir, se debe tratar de un aporte "cierto, claro, patente y sin la menor duda"63; por tanto, la contribución de la empresa debe haber sido determinante, de modo que sin ella la invención no se hubiera alcanzado ${ }^{64}$.

Esta exigencia se justifica si recordamos que la LPI presenta la invención mixta como una excepción frente a la invención libre -cuya titularidad, como se sabe, pertenece al trabajador-; de hecho, parte de la doctrina comparada considera a la mixta como una invención libre, que por sus características especiales concede ciertos derechos al empleador ${ }^{65}$. Por esto consideramos que la aportación de la empresa a la invención, a través de los conocimientos entregados al trabajador, debe haber predominado por sobre la iniciativa de este último. En los casos en que lo decisivo sea la aportación personal del trabajador, creemos debería aplicarse lo dispuesto en el art. 69 inc. $1^{\circ}$ de la LPI y, en consecuencia, la invención pertenecería a él y no a su empleador ${ }^{66}$.

Respecto de los "medios", a diferencia de los "conocimientos", ellos se refieren a un aporte de carácter material. En este sentido, la Real Academia Espańola entiende por medio una "cosa que puede servir para un determinado fin, como p. ej. medios de transporte, de comunicación" 67 .

PÉREZ (1994) 165.

PÉREZ (1994) 165.

63 Real Academia Española (2001). Disponible en línea: http://buscon.rae.es/draeI/ SrvltConsulta?TIPO_BUS=3\&LEMA=evidente [consultado el 27 de junio de 2011].

64 En el Derecho francés, Gridel considera que no se cumple el requisito de "beneficiarse" de los conocimientos cuando estos pertenecen al "dominio público" de la industria en la cual se desarrolla la invención, aunque sean desconocidos para el sujeto común (véase GrideL (1980) 44).

65 Esta idea ha sido defendida extensamente por la doctrina española. Véase, por todos, Feas (1987) 130; Rodríguez-Piñero (1986) 45; Lois (2000) 139; y Pérez (1994) 165.

66 Véase Feas (1987) 130, para quien -acertadamente- "La aportación de la empresa ha de ser particular, original y específica: instrumentos o máquinas exclusivos de esa empresa en concreto, y métodos y conocimientos desconocidos fuera de ella, incluso para otros profesionales del mismo sector empresarial".

67 Real Academia Española (2001). Disponible en línea: http://buscon.rae.es/draeI/ SrvltConsulta?TIPO_BUS=3\&LEMA=medio [consultado el 27 de junio de 2011]. 
En el ámbito de las invenciones, la doctrina comparada ha sostenido que se refiere a la contribución de la empresa derivada de la utilización de sus instrumentos, tales como microscopios, instrumentos de medición de alta precisión, máquinas de soldadura, entre otros, sin los cuales la invención no hubiera podido ser realizada ${ }^{68}$.

El inc. $2^{\circ}$ del art. 69 LPI dispone que dichos medios de la empresa deben ser "utilizados" por el trabajador con miras a conseguir la invención. De esta manera, este requisito no se cumple si aquellos solo ayudaron a obtener un conocimiento de cara a la invención, toda vez que -por hablarse de utilizar- se requiere la participación efectiva de estos en el proceso de confección del invento, o incluso ser parte de su propia composición. Compartimos asimismo la opinión de autores extranjeros en cuanto a que deben ser medios específicos de la empresa, por lo que utilizar materiales triviales o la biblioteca de la empresa, no permitiría calificar la invención como mixta ${ }^{69}$.

Por último, un aspecto de gran importancia es la distinción que debemos hacer entre la experimentación necesaria para conseguir la invención de aquella posterior a alcanzada la misma. Nos parece, siguiendo a García Vidal, que los experimentos o ensayos posteriores a la invención no debiesen ser considerados para efectos de calificar una invención como mixta. Por lo cual, si el empleador ha aportado simplemente medios para la realización de estas pruebas, no se convertiría en el titular de aquella ${ }^{70}$.

Como también apunta García Vidal, será necesario entonces delimitar el momento en que debe entenderse que se ha conseguido una invención, pues este marcará la línea divisoria a partir de la cual el uso de medios proporcionados por la empresa influirá en la calificación de la invención como perteneciente al empleador $\mathrm{y}$, a su vez, permitirá distinguir entre experimentación previa y posterior a la invención ${ }^{71}$. La solución parece encontrarse, siguiendo a este autor, en considerar que "la invención se habrá conseguido cuando se resuelva el problema técnico que se pretende solucionar con la misma, esto es, cuando se consiga la regla técnica" 72 .

68 Véase Lois (2000) 145. En el mismo sentido, Pérez (1994) 166-167, para quien en el concepto de "medios" no se deben incluir las materias primas.

69 Lema (1990) 150. En el mismo sentido, Pérez (1994) 166-167; Lois (2000) 146; y GriDEL (1980) 43.

70 García Vidal, Ángel (2007). "Las invenciones laborales libres y de servicio [Comentario a la sentencia de la Audiencia Provincial de Murcia, núm. 332/2006 (Sección 2a), de 12 de diciembre]". Actas de Derecho industrial y Derecho de autor, T. XXVII (2006-07), pp. 621644, p. 634.

71 García (2007) 634

72 García (2007) 634. Como explica este autor, "una vez que se pueda describir de manera suficientemente clara y completa la invención para que un experto en la materia pueda ejecutarla, hay que entender que ya estamos ante una invención”. 


\section{(2.2.3) Sobre la titularidad de la invención mixta}

Nuestro ordenamiento establece que la titularidad del invento, cuando concurran los requisitos antes señalados, pertenecerá al empleador, teniendo el trabajador derecho a una retribución adicional (sobre la naturaleza y características de esta retribución, véase 3.2.). Del tenor del inc. $2^{\circ}$ art 69 LPI se deduce que se trata de una titularidad originaria, a pesar que en la práctica - como ya señalamos al referirnos a las invenciones contratadas o por encargo- se suele efectuar la cesión del trabajador al momento de solicitar la respectiva patente.

Cabe apuntar que la legislación nacional, en lo que respecta a esta titularidad exclusiva del empleador, se aparta de las soluciones existentes en el Derecho comparado, en que mayoritariamente se consagra un derecho de opción para el empleador de "asumir" la invención (es decir, exigir su titularidad) o simplemente solicitar un derecho no exclusivo de uso de la misma $^{73}$. Otra solución es la del Derecho brasileño, en que el empleador solo tiene el derecho a una cotitularidad compartida con el trabajador $^{74}$.

73 En el Derecho alemán, para efectos de la titularidad de la invención, se distinguen simplemente entre invenciones "no libres" (que agrupan (i) a las que resultan de una actividad inventiva obligatoria del trabajador, y (ii) a las que se basen sustancialmente en la experiencia o actividades de la compañía, según dispone el $\$ 4$ (2) ArbnEfrG) y "libres" (definidas negativamente, como aquellas que no reúnen los requisitos anteriores, según dispone el $\$ 4$ (3) del mismo cuerpo legal). Las invenciones "no libres", dan al empleador la opción de solicitar ya sea la patente o un derecho no exclusivo de uso de esta $(\$ 6$ y $\$ 7)$. En el Derecho español, el art. 17.1 de su Ley de Patentes -que regula las invenciones mixtas- dispone que "(...) el empresario tendrá derecho a asumir la titularidad de la invención o a reservarse un derecho de utilización de la misma", norma que reconoce claramente que se trata de un derecho de opción para el empleador, que nace cuando se alcance una invención de esta naturaleza. En el Derecho francés, el artículo 611-7 del Código de Propiedad Intelectual (Code de la Propriété Intellectuelle) reconoce en su $\mathrm{N}^{\circ} 2$ que el empleador puede solicitar que se le "asigne" la titularidad de la invención del trabajador o que se le otorgue una licencia total o parcial sobre ella, en los casos en que este último, sin estar contratado para investigar, la haya alcanzado durante la ejecución de sus funciones. En el Derecho estadounidense, a falta de regulación legal expresa a nivel federal, se ha reconocido por la doctrina y jurisprudencia que en los casos en que el trabajador no haya sido contratado para investigar, pero haya alcanzado la invención utilizando las instalaciones y recursos de la empresa, aunque la patente le pertenecerá al trabajador, el empleador podrá obtener una licencia gratuita, no exclusiva e intransferible para fabricar y utilizar la invención, lo que se conoce como la doctrina del "shop right" (véase Gudmestad, Telje (1982). "Patent Law of the United States and the United Kingdom: A comparison". Loyola of Los Angeles International and Comparative Law Journal, № 5, pp. 173196, pp. 181-182, para quien se trata de una solución "intermedia", entre las invenciones pertenecientes al empleador y las libres). En el Derecho argentino, el artículo 10 letra b) de su Ley $\mathrm{N}^{\circ}$ 24.481, de Patentes de Invención y Modelos de Utilidad dispone que “(...) cuando el trabajador realizara una invención en relación con su actividad profesional en la empresa y en su obtención hubieran influido predominantemente conocimientos adquiridos dentro de la empresa o la utilización de medios proporcionados por esta, el empleador tendrá derecho a la titularidad de la invención o a reservarse el derecho de explotación de la misma".

74 La situación del Derecho brasileño es especialmente particular, en tanto su Ley No 9.279 (14 de mayo de 1996), sobre Propiedad Industrial, establece un régimen de copropiedad 
Claramente el legislador nacional se ha inclinado a favor del interés del empresario al concederle la titularidad sobre esta categoría de invenciones, a pesar que la actividad inventiva no forme parte de la obligación debida por el trabajador. Con todo, esta opción va de la mano con las mayores exigencias que de acuerdo al art. 69 inc. $2^{\circ}$ deben concurrir para que nos encontremos ante una invención mixta, según tuvimos oportunidad de analizar.

Esta concesión de la titularidad al empresario se ha justificado indicando que se trata de invenciones que pueden aparecer como "parasitarias", ya que el trabajador se ha servido de la posición laboral propia para realizar la invención, la que no hubiera sido posible para él de no ser dependiente de esa empresa"75. Otros autores, en tanto, consideran que su fundamento se encuentra en una tradicional disposición del Derecho de la competencia, según la cual se establece como prohibición que, con la ayuda de los medios proporcionados por el empresario, el trabajadorinventor se convierta en un competidor que explota la invención faltando a la fidelidad contractual ${ }^{76}$.

Este criterio no ha estado exento de críticas de la doctrina comparada. Un destacado sector no está de acuerdo con la solución de otorgar al empresario la titularidad de la invención, pues ella no se ha obtenido en el cumplimiento de una actividad debida. Se afirma por estos autores que lo más adecuado sería reconocer al empresario simplemente el derecho a obtener una licencia no exclusiva sobre dicho invento ${ }^{77}$.

Concordamos con dichas críticas toda vez que nos parece que en el supuesto de una invención mixta se le debieran conceder derechos al empleador -dado su aporte a la invención, aun cuando se trató de una con-

en el caso de las invenciones mixtas. Así, el artículo 91 de dicho cuerpo legal dispone que "La propiedad de invención o del modelo de utilidad será común, en partes iguales, cuando resultare de la contribución personal del empleado y de recursos, datos, medios, materiales, instalaciones o equipamientos del empleador, resguardada expresa disposición contractual en contrario". Versión en español, disponible en: http://www.inpi.gov.br/ menu-esquerdo/desenho/pasta_legislacao/lei_9279_espanhol_html [consultado el 20 de julio de 2011]. Para un análisis detallado del ordenamiento brasileńo en esta materia, véase Lois Bastida, Fátima (1999b). "La protección del inventor asalariado en el Derecho brasileño". Actas de Derecho Industrial y Derecho de Autor, T. XX, pp. 1.553-1.568, pp. 1.561 ss.

75 Rodríguez-Piñero (1986) 45. En el mismo sentido, Fernández Domínguez, Juan y Agra Viforcos, Beatriz (1997). "De las invenciones laborales". Tribuna social: Revista de seguridad social y laboral, $\mathrm{N}^{\circ}$ 83, pp. 29-44, p. 37; y PÉrez (1994) 166.

76 Véase Bercovitz (1976) 86; y Pérez (1994) 169.

77 Véase, en el Derecho español, Gómez (1984) 121; y BaYlos, Hermenegildo (1993). Tratado de Derecho Industrial. 2a Ed. Madrid: Civitas, 1.061 pp., p. 727. En el Derecho francés, RouBIER, Paul (1952-54). Le Droit de la Propriété Industrielle. París: Sirey, T. II, 854 pp., pp. 190-193. En el Derecho estadounidense, Van Slyke, Paul y Friedman, Mark (1990). "Employer's rights to inventions and patents of its officers, directors and employees". American Intellectual Property Law Association Quarterly Journal, $\mathrm{N}^{\circ} 18$, pp. 127-154, pp. 138 ss. 
tribución no consciente-, como precisamente sería el derecho a licencia antes mencionado, pero no una titularidad total sobre ella ${ }^{78}$. Tal solución representa una opción que se sitúa en un extremo dentro de las posibilidades. No solo porque priva completamente al trabajador de los derechos de la invención, sino también porque creemos perjudica también al empleador y, a la larga, a la innovación en general. Lo anterior, debido a que en un esquema como el chileno, estimamos que propicia la generación de conflictividad entre empleador y trabajador. Como hemos apuntado, en principio la invención mixta es una excepción a la libre, de manera que si al trabajador no se le reconoce ningún porcentaje de titularidad sobre la misma, en muchos casos pensará que se trata de una de carácter libre. Prueba de ello, es que uno de los pocos casos que han conocido nuestros tribunales sobre invenciones en servicio se refirió precisamente a una discusión acerca de si la invención era libre o mixta ${ }^{79}$. Propicia aun más dicha conflictividad, el que nuestra normativa no contemple ninguna obligación del trabajador de comunicar al empleador el que ha obtenido una invención de las características de una mixta, como sí ocurre en algunas legislaciones comparadas ${ }^{80}$.

En vista de lo expuesto, consideramos que un sistema de invención mixta que conjugue de manera más equilibrada los intereses de empresas y trabajadores, debiera contemplar las siguientes características. En primer lugar, una exigencia para el trabajador de comunicar a la empresa que ha conseguido una invención que posee los elementos de una mixta. En esta comunicación, el trabajador debería manifestar su intención, o bien de ser titular de un porcentaje de la patente (puede ser del 50\%, como el supuesto brasileńo), o bien ceder a la empresa por completo dicha titula-

78 Con todo, en la doctrina española se ha señalado que -conforme dispone el artículo 17.1 de su Ley de Patentes-, en caso que el empleador simplemente solicite una licencia no exclusiva de uso de la invención, el trabajador podría otorgar licencias a empresas competidoras, con lo que eventualmente se quebrantaría la buena fe que debe presidir las relaciones laborales (véase Lema (1990) 151).

79 Véase Tribunal de Propiedad Industrial, 28 de enero de 2009, Rol 1461-2003. Según lo dispuesto en el art. 72 de la LPI "(t)odas las controversias relacionadas con la aplicación de las disposiciones de este Título (VI) serán de competencia del Tribunal de Propiedad Industrial". Esta norma es bastante interesante, pues desde el punto de vista laboral, como se sabe, las cuestiones que se susciten entre empleadores y trabajadores por aplicación de normas laborales deben ser conocidas por los tribunales del trabajo (art. $420 \mathrm{CdT}$ ), en cambio para esta clase de asuntos se opta por entregar su decisión al un tribunal especial de propiedad industrial. Con todo, determinados aspectos eventualmente llegarán al conocimiento de los juzgados del trabajo (véase Corte Suprema, sentencia de 29 de noviembre de 2005, Rol 4169-2004. Disponible en jurisprudencia on line de LegalPublishing).

80 En el Derecho español, el artículo 18.1 de su Ley de Patentes, que se refiere a exclusivamente a las invenciones pertenecientes al empleador y a las mixtas, excluyéndose las libres. En el Derecho alemán, el $\$ 5$ de la ArbnEfrG, que se refiere a las invenciones pertenecientes al empleador y a las mixtas, y el $\$ 18$ del mismo cuerpo legal, que lo exige para las invenciones libres. En el Derecho francés, tal deber se encuentra en el artículo el artículo 611-7 No 3 del Código de Propiedad Intelectual. 
ridad. Puesta en conocimiento, la empresa tendría que decidir entre ser o no titular (total o parcialmente) de la invención, lo que debería implicar acarrear en buena parte con los costos de puesta en marcha y comercialización de la invención. Si la empresa decide no hacer uso de la opción mencionada, de todas maneras tendría derecho a un uso no exclusivo de la utilización de la patente por un plazo determinado.

\section{(2.3) LAS INVENCIONES LIBRES (ART. 69 INC. $1^{\circ}$ LPI)}

El tercer tipo de invenciones en servicio se refiere a las que son de titularidad exclusiva del trabajador, que se conocen comúnmente como invenciones libres ${ }^{81}$. Se encuentran contempladas en el art. 69 inc. $1^{\circ}$ de la LPI, a cuyo tenor "el trabajador que, según su contrato de trabajo, no se encuentra obligado a realizar una función inventiva o creativa, tendrá la facultad de solicitar el registro, así como los eventuales derechos de propiedad industrial derivados de las invenciones realizadas por él, los que le pertenecerán en forma exclusiva". Como dijimos en apartados precedentes, si bien dicha norma se refiere en principio al trabajador que no se encuentra "obligado a realizar una actividad inventiva o creativa", debiera también entenderse comprendido en ella a aquel trabajador que realiza una invención -libre- originada en una investigación que no es parte de la misión investigativa estipulada en el contrato.

La noción de las invenciones libres es residual, pues para que nos encontremos ante ellas es necesario que no concurran los presupuestos establecidos para la invención contratada o por encargo (art. $68 \mathrm{LPI}$ ), como tampoco aquellos correspondientes a la invención mixta (art. 69 LPI) ${ }^{82}$. La investigación que le dará origen no puede entonces ser parte del objeto del contrato de trabajo, como tampoco el trabajador (no contratado para investigar) podrá beneficiarse de modo evidente de los conocimientos adquiridos dentro de la empresa, ni utilizar medios proporcionados por esta. En definitiva, la invención libre tiene su fuente fuera del ámbito de la empresa, es decir, en investigaciones privadas de su autor ${ }^{83}$.

La importancia de la declaración de esta clase de invenciones consiste en que no influye su carácter de "libre" el hecho que haya sido concebida por el trabajador mientras presta servicios como dependiente en una empresa $^{84}$. En este sentido, cabe a apuntar que este derecho reconocido a los trabadores a desarrollar sus propias invenciones -ajenas a su contrato de trabajo- es seguramente uno de los aspectos donde tendría mayor apli-

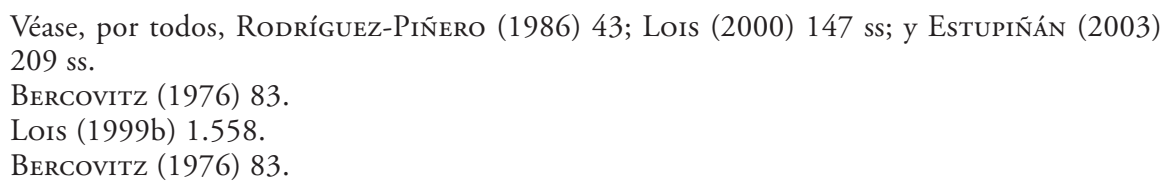


cación el principio de irrenunciabilidad de derechos de los trabajadoresinventores, contemplado en el art. 71 de la LPI. Y es que claramente la titularidad de estas invenciones no podría ser objeto de renuncia en favor del empleador antes de la obtención de la patente. Con todo, es probable que no nos encontremos con cláusulas expresas en dicha dirección, pues sería sencillo percibir su contradicción con el principio en cuestión, sino, más bien, se trataría de situaciones donde de forma encubierta se produce dicha vulneración. Pensamos que un buen ejemplo se daría en el caso de invenciones contratadas o por encargo en que se recurra a cláusulas de invención muy amplias. Dado que éstas podrían afectar inventos que han sido desarrollados por el trabajador en forma exclusiva, y que no guardan relación con sus tareas dependientes.

\section{3) REMUNERACIÓN DEL TRABAJADOR-INVENTOR}

En el ámbito de las invenciones en servicio, junto con la determinación de su titularidad, uno de los aspectos que presenta mayor importancia se refiere al régimen retributivo de los trabajadores-inventores, en particular la denominada "retribución adicional" (art. 69 inc. $2^{\circ}$ y final LPI) que puede operar en los casos de invenciones contratadas o por encargo y mixta. Una vez reconocida la titularidad empresarial de la patente, el punto a tratar por las partes consistirá en si dicho estipendio procede $y$, si es así, cuál sería su monto o base de determinación. Es una clase de remuneración interesante porque presenta características que escapan de los cánones comunes de aquellas contempladas en el CdT, lo que nos parece amerita un análisis en cuestiones tales como su naturaleza jurídica, procedencia y formas de determinación.

\section{(3.1) RÉGIMEN RETRIBUTIVO DE LAS INVENCIONES CONTRATADAS O POR ENCARGO}

\section{(3.1.1) Remuneración ordinaria}

El art. 68 LPI relativo a las invenciones contratadas o por encargo, no hace mención alguna relativa a la remuneración que deberá recibir el trabajador contratado para realizar una actividad inventiva, aun cuando se logre un invento. En principio nos parece que el trabajador solo tendrá derecho a la remuneración pactada para su función inventiva en el contrato, a pesar que finalmente se obtenga un resultado. $Y$ es que, según veremos, la remuneración adicional procede en forma exclusiva cuando la invención haya excedido de aquello que ha sido encargado (art. 69 inc. final LPI). Por lo demás, este era el criterio seguido por el anterior Reglamento de la LPI (Decreto Supremo N 177/Min. Economía, hoy derogado), que 
a este respecto disponía que "el trabajador (...) solo tendrá derecho a la remuneración o retribución señalada en el respectivo contrato de trabajo o de prestación de servicios" (art. 111).

En este sentido, parte relevante de la doctrina comparada apunta que la remuneración ordinaria que percibe el trabajador cubre, en principio, todas aquellas actividades que son parte del objeto del contrato, entre ellas, las de carácter inventivo. Se sostiene que, en estos casos, el trabajador es remunerado por la actividad de investigación, y no por el resultado de ella ${ }^{85}$; en cambio, el empresario debe soportar el riesgo de tareas desarrolladas por sus trabajadores, con independencia de los logros que puedan conseguir ${ }^{86}$. Por ello se afirma que el trabajador está ciertamente remunerado y contratado para investigar, de tal manera que la consecución de la invención constituye el resultado esperable de la actividad debida. De esta suerte se concluye que, en principio, la invención no es el fundamento para algún tipo de remuneración suplementaria, toda vez que no sería justo recompensar a una persona por hacer aquello para lo que se le ha contratado ${ }^{87}$. Con todo, nada obstaría para que se fijen suplementos remuneracionales destinados a incentivar la concreción de invenciones, ya sea en el contrato individual de trabajo o en un instrumento colectivo ${ }^{88}$.

\section{(3.1.2) Retribución adicional}

(a) Fundamentos de su reconocimiento legal

El inc. final del art. 69 LPI contempla la posibilidad que el trabajador tenga el derecho de recibir una cantidad mayor de aquella estipulada en su contrato, siendo la condición habilitante para ello el que se logre una "invención que exceda el marco de la que fue encargada"; para esto la norma citada se remite al inc. 2 del art. 68 relativo a la invención mixta, que genera el derecho a una retribución adicional ${ }^{89}$.

\footnotetext{
85 Véase SALa/Vicent (1988) 1.986

86 Véase Albiol (1975) 112; y Pedemonte Feu, Jorge (1988). Comentario a la Ley de Patentes. Barcelona: Bosch, 418 pp., p. 43.

Gómez (1984) 123 ss.

ESTUPIŃÁN (2003) 188.

El inc. final del art. 69 LPI, relativo a la retribución adicional, está dirigido a complementar el art. 68 LPI, que, como hemos visto, trata la titularidad de la invención contratada o por encargo. Recordemos, que la invención por encargo se caracteriza porque fue el resultado de una actividad investigativa que era parte del objeto del contrato de trabajo. De forma tal, que el contenido de ese objeto es la realización de una actividad inventiva o creativa, pero no la consecución de una determinada invención. Del tenor la primera norma, en particular de la expresión "que le hubiere sido encargada", se deduce a primera vista que se requiere que el objeto del contrato consista en la concreción de una invención, es decir, se trataría de una de obligación de resultado. Pero ello se contrapone con los términos del art 68 LPI (al cual complementa el inc. final del art. 69 LPI) que no exige tal concreción, sino que el objeto del contrato
} 
La existencia esta clase de retribución se justifica, en buena medida, en que la actividad inventiva siempre va dirigida hacia lo desconocido ${ }^{90}$, y en ese camino su resultado -que muchas veces no se consigue- puede ser ciertamente relevante, lo que importaría para la empresa una ganancia que vaya más allá de los parámetros predecibles.

En este sentido, resulta ilustrativo el caso de Shuji Nakamura, inventor de la tecnología del LED azul (Light-Emitting Diode o "diodo emisor de luz" azul). El señor Nakamura desarrolló esta invención mientras era dependiente de la empresa japonesa Nichia Corporation. Por este revolucionario logro, dicha compañía obtuvo una ganancia enorme -cerca de USD 1.400.000.000-, pero su inventor no recibió remuneración adicional alguna. Ante tal situación, Nakamura decidió demandar a la empresa Nichia con miras a conseguir una remuneración justa, considerando las utilidades que había reportado su invento. La Corte Distrital de Tokio reconoció el derecho del señor Nakamura a recibir una compensación que fuera más equitativa, y fijó su monto en USD 190.000.000 ${ }^{91}$. Posterior-

consista en una actividad inventiva o creativa, esto es, una obligación de medios. Recordemos que conforme a la naturaleza del contrato de trabajo, el trabajador no asume una obligación de resultado, sino de medios. Como apunta en la doctrina nacional Macchiavello, el objeto de la obligación del trabajador no es un "resultado", sino "un hacer", que este define como "actividad laborativa" (Macchiavello Contreras, Guido (1986). Derecho del Trabajo. Santiago: Fondo de Cultura Económica, T. I, 546 pp., p.169). En el mismo sentido, Alonso Olea y CASAS BAAMONDE afirman que "la deuda contractual del trabajador es una deuda de actividad y no de resultado, por mucho que aquella luzca en este" (Alonso/Casas (2006) 71). No se debe entonces un resultado, sino más bien el desarrollo de una actividad productiva en interés del acreedor, actividad que debe ser controlada según criterios de diligencia y habilidad (BARreiro González, Germán (1981). Diligencia y negligencia en el cumplimiento. Estudio sobre la prestación del trabajo debida por el trabajador. Madrid: Centro de Estudios Constitucionales, 420 pp., p. 152). Con todo, la actividad del trabajador puede ir dirigida a conseguir una prestación o resultado determinado, pero debe tratarse de uno "esperado" empleando la diligencia debida. De esta forma, el trabajador se compromete a realizar una actividad -actuación diligente- considerada en sí misma y tendente a conseguir un fin, aunque el logro efectivo de este no sea debido (Trigo García, María Belén (1999). Contrato de servicios. Perspectiva jurídica actual. Granada: Comares, 424 pp., p. 186); no asegura el resultado, sino la adopción de las medidas adecuadas, normalmente conducentes a su obtención (Trigo (1999) 186). Se da así, una conexión entre actividad y resultado en la relación de trabajo. Por tanto, creemos que el inc. final del art. 69 LPI debe ser entendido en orden a que el exceso consista en una aportación extraordinaria del trabajador en su trabajo (que da origen a la invención), pero no en clave que lo exigido sea una invención determinada.

$90 \quad$ Véase nota 29.

91 Para un extenso análisis de este caso, véase Johnstone, Bob (2007). Brilliant! Shuji Nakamura and the Revolution in Lighting Technology. Nueva York: Prometheus Books, 336 pp., pp. 232 ss. El autor destaca el efecto que tuvo la demanda de NaKamura en Japón, en tanto fue el punto de partida para que muchos inventores nipones comenzaran a demandar a sus empleadores con el objeto de obtener una "remuneración justa" por sus creaciones. Cabe destacar que Nakamura también solicitó que se le devolviera un porcentaje de la titularidad de la patente clave para la tecnología del LED azul, que a esa fecha estaba a nombre de Nichia. Esta solicitud fue rechazada por la Corte Distrital de Tokio, que estimó que en virtud del contrato de trabajo que lo ligaba con la empresa al momento de la invención, se le atribuía su titularidad a ella. 
mente, mientras estaba pendiente un recurso interpuesto por la empresa, las partes llegaron a un acuerdo por un total de USD 8.000.00092.

El ejemplo anterior pone de manifiesto que en este ámbito es posible que se produzca una descompensación entre las prestaciones recíprocas propias del contrato de trabajo. En efecto, Macchiavello apunta que los inventos son un caso típico en que el producto propio de un trabajo puede tener una mayor significación que el pago correlativo de los servicios ${ }^{93}$.

Esta situación puede generar el quiebre de una de las características propias del contrato de trabajo como es la conmutatividad, pues las obligaciones contraídas por las partes se miran como equivalentes (art. 1441 Código Civil ${ }^{94}$. Es por eso que consideramos que el objetivo de esta norma se encontraría en la búsqueda de la conmutatividad que se pierde, cuando la investigación contratada llega a un resultado (invención) que sobrepasa las estimaciones que se pensaban al momento de suscribirse el contrato ${ }^{95}$.

Se trata entonces de una búsqueda del equilibrio obligacional en beneficio del trabajador, pues de no existir esta norma solo se tendría derecho a percibir la remuneración ordinaria estipulada en el contrato. Ciertamente, ello se corresponde con lo señalado por Gamonal en cuanto a que se acepta que en ciertos casos esta conmutatividad se afecte pero siempre que sea en favor del trabajador, dado el carácter tutelar del Derecho del Trabajo ${ }^{96}$.

(b) Origen y determinación de la remuneración adicional

Desde la perspectiva de la operatividad de esta retribución adicional es necesario examinar dos temas. En primer lugar, cuándo se genera este derecho y, en segundo orden, la determinación de su monto o bases de cálculo. A continuación trataremos cada uno de ellos.

\section{(b.1) Procedencia de la retribución}

Según veíamos, el derecho a la retribución adicional se devenga cuando el trabajador desarrolla un trabajo (misión inventiva) que excede

\footnotetext{
92 Véase Johnstone (2007) 241. A juicio del autor, la radical diferencia entre la suma determinada por el tribunal y aquella alcanzada en el acuerdo se debe a la influencia del abogado de Nakamura, que lo instó a aceptar una menor remuneración adicional, ante la posibilidad que la decisión de la Corte Distrital de Tokio fuera revertida en instancias superiores. Macchiavello (1986) 31.

GAMONAL/Guidi (2010) 7.

Véase Blanco (1999) 118, para quien el fundamento de esta remuneración adicional "se encuentra en la búsqueda del equilibrio cuantitativo entre las prestaciones del empleado y del empleador, de forma que se facilite la comunicación de invenciones al empleador y la cooperación entre ambas partes"

96 Véase Gamonal (2008) 22-23.
} 
en forma positiva la prestación pactada y que producto de ese trabajo se obtiene una invención.

Bajo este esquema, podemos sostener que nuestro ordenamiento sigue el principio de "la prestación extraordinaria" gislaciones como la chilena o la española entienden que la invención es consecuencia del normal desarrollo de la prestación laboral, por lo cual el trabajador ya ha recibido remuneraciones en las que se han tenido en cuenta sus capacidades inventivas. Por ello, aquel solo tendrá derecho a una remuneración adicional si su aportación personal se presenta como extraordinaria, teniendo en cuenta la naturaleza de las obligaciones contratadas $^{98}$.

Un sector de la doctrina comparada no se muestra conforme con este principio, ya que estima que lo justo, con miras al interés de los inventores y de quienes los contratan, es que el nacimiento de aquella retribución dependa de la rentabilidad de la patente; de modo que resulta acertado que el trabajador-inventor participe en los beneficios extraordinarios, pero no correspondería conceder una indemnización al inventor bien retribuido, al margen del rendimiento económico de la invención. Este esquema de retribución basado en los beneficios derivados de la explotación de la patente, se denomina "el principio del monopolio o de la rentabilidad de la patente" 99 .

Por su parte, los autores que siguen el primer criterio ("principio de la prestación extraordinaria”), rechazan el sistema del principio del monopolio, porque entienden que la remuneración suplementaria quedaría totalmente al arbitrio del empresario, pues este puede decidir no explotar la invención, o hacerlo en forma limitada, en cuyo caso, el trabajador podría verse defraudado en su derecho a la eventual recompensa que pudiera corresponderle por los beneficios derivados de la explotación de la invención ${ }^{100}$.

Véase Bercovitz (1976) 86; Pérez (1994) 301-302; y Gridel (1980) 58.

Véase artículo 15.2 de la Ley de Patentes espańola, según el cual "El trabajador, autor de la invención, no tendrá derecho a una remuneración suplementaria por la realización, excepto si su aportación personal a la invención y la importancia de la misma para la empresa exceden de manera evidente del contenido explícito o implícito de su contrato o relación de trabajo". La doctrina espańola considera que esta disposición da cuenta de la recepción del "principio de la prestación extraordinaria" en el Derecho español (véase, por todos, LoIs (2000) 191-192; y Pérez (1994) 303-304).

99 Véase Gómez (1984) 124; y Pellisé Prats, Buenaventura (1985). Informe analítico sobre el Proyecto de Ley de Patentes de 1985. Barcelona: Centro de Estudios para el fomento de la investigación, 68 pp., p. 24. Cabe destacar que este principio se encuentra recogido tanto en el Derecho alemán ( $\$ 9$ ArbnEfrG) como en el Derecho danés ( $\$ 8$ Lov om arbejdstageres opfindelser-Ley de invenciones laborales danesa-).

100 Véase Bercovitz (1976) 86. Por su parte, Gómez Segade rechaza este argumento, por considerar que si el empresario no explota la invención será porque estima que no es rentable (véase Gómez (1984) 125). 
Como hemos apuntado, el art. 69 LPI dispone que la retribución adicional procede cuando se consigue "una invención que exceda el marco de la que le hubiere sido encargada". Dados estos términos, podemos señalar que esta norma es menos exigente para el trabajador que otras similares de Derecho comparado con un esquema análogo. Así p. ej., en el Derecho argentino y español, se necesita que concurran copulativamente tanto una prestación extraordinaria del inventor, como que ella sea de importancia para la empresa, con el agregado que ambas exigencias sobrepasen de forma "evidente" el contenido del contrato (art. 10 letra b) Ley de Patentes argentina y art. 15.1 Ley de Patentes española).

En cambio, la ley chilena no hace mención alguna relativa a que el exceso en la aportación de trabajo presente una determinada intensidad -p. ej. que sea evidente o manifiesto-, como tampoco a que este tenga importancia para la empresa. De todas formas, a nuestro entender como se trata de la retribución adicional de la invención contratada o por encargo -y no de la mixta-, este exceso de trabajo (que da derecho a la retribución adicional) debería presentar cierta entidad, pues de no ser así tendría que estar cubierto por las remuneraciones indicadas.

Para determinar si estamos en presencia del exceso requerido, nos parece que es necesario tener en cuenta el concepto de diligencia debida por el trabajador. A este respecto, Barreiro señala que el trabajador debe realizar su prestación con el empleo de la diligencia exigible, de modo que está obligado al desarrollo y ejecución de la prestación en cuanto esta (o hasta la altura en que la misma) pueda ser cumplida y satisfecha mediante su actuación diligente; así, el trabajador no estaría obligado a realizar aquella prestación que implique rebasar lo debido de su diligencia ${ }^{101}$. Conforme con ello, nos parece que el exceso debe referirse a aquellos casos en que el trabajador extralimite los marcos de una actuación diligente, de modo que realice actuaciones respecto a las que no estaba obligado. Y es que si se habla de exceso, debe tratarse de una prestación que no era parte del contrato, pero sí que puede estar ligada a la obligación contratada. En efecto, la aportación personal del trabajador ha de ir más allá de lo exigido en el contrato, y la importancia de la invención ha de ser mayor que los resultados de una invención normal a cuyo sostenimiento ya contribuye el empresario.

Por consiguiente, es posible advertir que estas circunstancias cualitativas tienen unos contornos tan borrosos que será difícil que surja el derecho a esta remuneración adicional, razón por la cual algunos autores de Derecho comparado consideran más apropiado designar a esta retribución como "extraordinaria" 102.

\footnotetext{
101 Barreiro (1981) 152-153.

102 PÉREZ (1994) 304-305.
} 


\section{(b.2) Determinación de su monto o bases de cálculo}

Una de las mayores dificultades prácticas que surgen en torno a la remuneración es lograr una fórmula lo más exacta y equitativa posible con miras a compensar una prestación de servicios dependiente ${ }^{103}$. A este problema procuran dar respuesta los diversos tipos de remuneraciones que han ido surgiendo y que, en la práctica, se van utilizando en función de los caracteres de la prestación de servicios que pretenden compensar; todos los cuales intentan buscar la equivalencia trabajo-salario ${ }^{104}$, con miras a "influir directamente en la producción y atraer, retener e incentivar a los trabajadores" 105 .

Precisamente, tratándose de la retribución adicional uno de los aspectos que presenta mayor complejidad se refiere al tema de su determinación. Conforme lo dispuesto en el inc. $2^{\circ}$ del art. 68 LPI (dada la remisión efectuada a este por el inc. final del art. $69 \mathrm{CdT}$ ), esta retribución debe ser fijada por "el acuerdo de las partes". Para ello la ley no establece ningún tipo de lineamiento donde las partes puedan orientarse, ni tampoco al tribunal que finalmente deba conocer la cuestión si ellas no llegan a un acuerdo. Recordemos que el Reglamento derogado señalaba que esta retribución se debía fijar en función de "la importancia comercial e industrial de la creación" (art. 112 inc. $2^{\circ}$ Decreto Supremo No 177/Min. Economía).

Para estos efectos, siguiendo a Pérez nos parece necesario comprobar en qué medida el valor de la invención excede de las retribuciones ordinarias recibidas por el trabajador-inventor; si, efectuado ese cálculo, se produce un resultado favorable al valor de la invención, procedería el pago de la retribución adicional ${ }^{106}$; de esta manera, coincidimos con el Reglamento derogado, en cuanto a que el dato clave vendría a ser la importancia industrial y comercial del invento. Cabe tener en cuenta que la remuneración ordinaria del inventor no se calcula en atención a la obtención de una invención importante para la empresa porque ello le daría un matiz aleatorio, que iría en contra de su esencia ${ }^{107}$. En tanto, si la importancia económica de la invención no sobrepasa los costes invertidos, la diferencia negativa deberá ser asumida por el empleador; o, dicho de otra forma, los ingresos del trabajador pueden acrecentarse por el hecho de la retribución adicional, pero no disminuir si no se cumplen las condiciones para que opere dicha retribución ${ }^{108}$.

\footnotetext{
103 Llompart Bennassar, Magdalena (2007). El salario: concepto, estructura y cuantía. Madrid: La Ley, 740 pp., pp. 319.

104 LlOMPART (2007) 319

105 Fariña Quezada, Lautaro (2010). Regulación del sueldo en el Código del Trabajo. Santiago: LegalPublishing, 170 pp., pp. 27-28.

106 PÉrez (1994) 320-321.

107 PÉREZ (1994) 321.

108 PÉrez (1994) 321.
} 
Consideramos que en la búsqueda de fórmulas que orienten a la determinación de esta retribución, pueden resultar muy útiles los criterios desarrollados por la legislación alemana que, sin lugar a dudas, debe ser uno de los ordenamientos comparados que mayor atención presta a esta materia. Brevemente, podemos indicar que el sistema de determinación de la remuneración adicional en el Derecho alemán se encuentra consagrado en los $\$ 9$ a 12 de la ArbnEfrG. En primer lugar, el $\$ 9$, en su apartado 1, reconoce el derecho del trabajador a una "compensación justa" cuando el empleador haya optado por solicitar la titularidad de la invención, mientras que en su apartado 2 dispone que para el cálculo de esta compensación se tendrán en cuenta especialmente la explotabilidad comercial de la invención, la posición del trabajador en la empresa y el grado de participación de la empresa en la creación de la invención. Dicha compensación también procederá, mutatis mutandis, cuando el empleador haya solicitado simplemente una licencia de uso no exclusiva de la invención ( $\$ 10$ ArbnEfrG). La determinación de su monto se encuentra asignada en primer término a las partes, sin perjuicio que eventualmente se podrá resolver la disputa en un proceso de conciliación o arbitraje ( $\$ 12$, en relación a los $\$ 28$ ss ArbnEfrG). Con todo, lo interesante de la regulación alemana es que el $\$ 11$ ordenó al Ministerio Federal del Trabajo alemán que dictara guías referidas a la determinación de esta compensación, lo que significó la creación de las llamadas "Guías para la remuneración de las invenciones de los trabajadores del sector privado" 109,110 .

109 Richtlinien für die Vergütung von Arbeitnehemererfindungen im privaten Diest, del 20 de julio de 1959, modificado el 1 de septiembre de 1983. En su introducción se destaca expresamente que estas no son obligatorias, sino que simplemente "guías" que ayudan a determinar el monto de remuneración adicional que corresponderá al trabajador. En ellas se seńala que para determinar la remuneración que deberá pagarse al trabajador se estará al producto de la multiplicación entre lo que se denomina el "valor de la invención" y una proporción, que se determina básicamente conforme a los siguientes parámetros: el nivel de iniciativa del trabajador en la determinación, la solución del problema y su posición de la empresa. Para llegar al "valor de la invención", las Guías contienen tres criterios sumamente útiles (más uno de carácter excepcional): la analogía con la licencia -contraprestación que recibiría el inventor libre por concepto de licencias de su invención-, el más utilizado en la práctica; el provecho esperable para la empresa -ventajas económicas derivadas de la invención, representadas en ahorro de costos o ingresos complementarios-; la estimación del valor de la invención -la medida en que ella es útil para la empresa-; y, excepcionalmente, la analogía en el precio de compra de otra invención -comparación con el valor de mercado de otra invención en el mismo sector-. Para un análisis de estos criterios, véase Pérez (1994) 317-318; Reitzle et al. (2007) 9 ss; y, en detalle, Trimborn, Michael (2009). Employees' inventions in Germany. Munich: Kluwer Law International, 196 pp., pp. 37 ss.

110 Véase Lors (2000) 200-201 y 205 ss, quien critica la falta de directrices o guías en el Derecho español, que ayuden a determinar el monto de la remuneración adicional a la que eventualmente tendrá derecho el trabajador. 
(b.3) Naturaleza de la remuneración adicional en las invenciones contratada o por encargo

En la doctrina comparada no es una cuestión pacífica la calificación de esta retribución adicional como remuneración. Existen autores que sostienen que debe considerarse como tal, pues se trata de un estipendio vinculado a la obtención de resultados individuales o colectivos que premian una "dedicación extraordinaria o un rendimiento superior a los normales"111. En cambio, otro sector no concuerda con dicha visión, pues estima que la retribución adicional no tiene carácter obligatorio dado que la invención por contratada o por encargo se realiza durante el normal desarrollo de la actividad investigadora. De esta forma, esta retribución solo se concibe en orden a evitar un enriquecimiento injusto del empleador, titular de una invención obtenida por la actividad del trabajador que sobrepasa el contenido de su contrato ${ }^{112}$.

En lo que respecta a nuestro ámbito laboral, creemos que esta retribución adicional puede calificarse como remuneración. En efecto, las condiciones personales del trabajador individualmente considerado pueden determinar que el mismo posea una aptitud para realizar el trabajo contratado superior a la que se estima normal entre quienes realizan la misma actividad en iguales condiciones ${ }^{113}$. Por consiguiente, en el desarrollo de un contrato de trabajo siempre es posible que un trabajador supere el rendimiento que se espera de él ${ }^{114}$; ello se traduce a la larga en reconocimientos que van desde ascensos, hasta mayores ingresos. Un buen ejemplo de nuestro ordenamiento laboral donde se reconoce que los trabajadores pueden realizar actividades extraordinarias que suelen estar fuera de sus funciones ordinarias y que conllevan igualmente una remuneración especial, se contiene en el art. $125 \mathrm{CdT}$ relativo a los trabajadores embarcados o de gente de mar, a cuyo tenor "a los oficiales y tripulantes que después del naufragio hubieren trabajado para recoger restos de naves o lo posible de la carga se les pagará, además una gratificación proporcionada a los esfuerzos hechos y a los riesgos arrostrados para conseguir el salvamento".

111 Álvarez (2008) 141-165. En el mismo sentido, véase Estupiñán (2003) 193-195; y Pérez (1994) 304 ss.

112 Véase Blanco (1999) 123. Sala/Vicent (1988) 1.986, por su parte, estiman que la naturaleza de esta remuneración adicional es extrasalarial e indemnizatoria.

113 Gárate Castro, Francisco (1984). El rendimiento en la prestación de trabajo. Madrid: Civitas, 323 pp., p. 187

114 Así p. ej. en España existen convenios colectivos en los que se regula un incentivo como cantidad a percibir en función de un rendimiento superior al normal. Véase, en este sentido, Mercader Uguina, Jesús (2004). "Retribución variable y cambios productivos". En Aparicio Tobar, Joaquín. Estudios sobre el salario (coordinador). Albacete: Bomarzo, pp. 87-109, p. 95 . 
Conforme lo señalado, en el caso de la retribución adicional de la invención por encargo, el exceso de trabajo exigido para su procedencia, no puede entenderse extramuros de la relación laboral donde se materializa, toda vez que la propia ley se sitúa incluso en el supuesto que tal situación se produzca, y de ahí que contempla el derecho a dicha retribución (inc. final art. 69 LPI). De este modo, existe una clara conexión entre los servicios prestados y los estipendios pagados por ello, que llevaría -de acuerdo a la definición de contrato de trabajo (art. $7^{\circ} \mathrm{CdT}$ ) - a calificar estos últimos como remuneración. Esto se confirma teniendo en cuenta la noción legal de remuneración, que es bastante amplia al comprender toda las contraprestaciones en dinero que debe percibir el trabajador "por causa del contrato de trabajo" (art. $41 \mathrm{CdT})^{115}$.

\section{(3.2.) RÉGIMEN RETRIBUTIVO DE LAS INVENCIONES MiXTAS}

\section{(3.2.1) Remuneración adicional. Procedencia y determinación}

Dada la técnica legislativa utilizada, podría pensarse que tanto la retribución adicional de la invención por encargo como aquella de la invención mixta, representan el mismo estipendio, pero desde ya adelantamos que ello no es así. En efecto, en la primera se trata de un trabajador que está contratado para realizar una tarea investigativa y que debido a un exceso en dicha actividad -que dio origen a un invento- se hace acreedor a la retribución adicional. En cambio, en el caso de las invenciones mixtas, el trabajador no está contratado para desarrollar la actividad mencionada, sino que consigue una invención sobre la base de los conocimientos y medios proporcionados por la empresa. Por consiguiente, en esta relación laboral no se prevé que el trabajador desarrolle una invención.

Como se trata de una invención mixta aquí no puede hablarse de exceso de trabajo, sino más bien del desarrollo de una labor en paralelo a la contratada, cuyo resultado es la invención. Entonces, cualquiera sea la invención que se obtenga, devengará el derecho al trabajador a una retribución adicional. Veíamos que este razonamiento en el supuesto de la invención contratada o por encargo no resulta sencillo, pues puede entenderse que no hubo exceso de trabajo requerido, y que la actividad que dio origen a la invención no fue más allá del marco contratado, de manera que el trabajador solo tendría derecho a su remuneración ordinaria.

115 Por su parte, el inc. $2^{\circ}$ del art. 41 del CdT, dispone que no constituyen remuneración "las asignaciones de movilización, de pérdida de caja, de desgaste de herramientas y de colación, los viáticos, las prestaciones familiares otorgadas en conformidad a la ley, la indemnización por años de servicios establecidas en el artículo 163 y las demás que proceda para al extinguirse la relación contractual ni, en general, las devoluciones de gastos en que se incurra por causa del trabajo". 
Resulta más probable, entonces, que el inventor de una invención mixta tenga derecho a recibir esta retribución, que aquel de la invención contratada o por encargo ${ }^{116}$.

En cuanto a su determinación, como sucede con la retribución adicional de la invención por encargo, esta retribución se tiene que fijar por "el acuerdo de las partes" (art. 68 inc. $2^{\circ}$ LPI). Según decíamos, la ley no contempla criterio alguno para orientar en este sentido, ya sea a las partes o al tribunal que deba conocer en caso de desacuerdo. Una pista se contemplaba en el Reglamento derogado que indicaba que su determinación debía efectuarse sobre la base de "la importancia comercial e industrial de la creación” (art. 112 inc. $2^{\circ}$ Decreto Supremo N 177/Min. Economía).

A diferencia de la remuneración adicional de la invención contratada o por encargo, aquí no se exige una prestación extraordinaria para que esta proceda, sino que cualquiera sea la invención mixta que se alcance, el trabajador tendrá derecho a ella. En cuanto a su determinación, estimamos que este análisis debería centrarse en la importancia de la invención misma desde el punto de vista comercial e industrial -como señalaba el antiguo Reglamento- y que entendemos debe importar las posibilidades concretas de explotación económica de la invención ${ }^{117}$; siendo ilustrativos en este sentido los criterios desarrollados en el ordenamiento alemán, antes vistos.

\section{(3.2.2) Naturaleza jurídica de esta remuneración adicional}

En relación a la naturaleza de la retribución adicional de las invenciones mixtas, consideramos que su calificación como remuneración es una cuestión que puede resultar discutible. Si tenemos en cuenta la definición de contrato de trabajo donde se deduce que la causa de la remuneración es el pago de los servicios personales a los que se compromete el trabajador (art. $7^{\circ} \mathrm{CdT}$ ), y nos centramos solo en esta conexión ("remuneración-servicios"), se tendría que concluir que para que un estipendio sea calificado como remuneración es necesario que esté relacionado con un servicio contratado que está siendo compensado. Como se ha observado, la retribución adicional no tiene conexión con servicios contratados, ni con sus resultados esperados, de modo que ella está cubriendo una cuestión ajena a dicha conexión, y así se ha entendido por un sector relevante de la doctrina comparada en cuanto a que no se podría concebir como remuneración ${ }^{118}$.

\footnotetext{
116 Gómez Segade, José Antonio (1998). "Remuneración por invenciones laborales y prescripción de acciones derivadas de la patente [comentario a la Sentencia de la audiencia provincial de Burgos de 20 de junio de 1997, "Azagra c. Rhone Poulenc Nutrición Animal, S.A."]". Cuadernos de jurisprudencia sobre Propiedad Industrial, No 17, pp. 13-27, p. 22. 117 Lois (2000) 209.

118 Véase, en este sentido, SALA/Vicent (1988) 1.987; Lois (2000) 204-205; y Estupiñán (2003) 205
} 
Con todo, si consideramos la definición de remuneración de nuestro CdT, es posible apreciar que ella amplía su noción no solo a aquella conexión "remuneración-servicios", sino a toda contraprestación que debe percibir el trabajador del empleador "por causa del contrato de trabajo" (art. $41 \mathrm{CdT}$ ). Existen varios ejemplos en nuestra legislación donde el empleador paga una remuneración a un trabajador aun cuando este no preste sus servicios; entre otros, podemos mencionar: el feriado legal (art. $67 \mathrm{CdT}$ ), los permisos para el padre por nacimiento de un hijo (195 inc. $2^{\circ} \mathrm{CdT}$ ), muertes de parientes (art. $66 \mathrm{CdT}$ ), si el juez ordena la separación de un trabajador de la empresa durante un juicio de desafuero con derecho a remuneración (art. 174 inc. $2^{\circ} \mathrm{CdT}$ ), y el pago de permiso sindical por la empresa por pacto individual o colectivo (art. 250 inc. final $\mathrm{CdT})^{119}$.

A su vez, existen desembolsos que tampoco obedecen al pago de servicios. Quizás el supuesto más ilustrativo en nuestra legislación viene a ser el "bono de reemplazo" durante la huelga; que, como se sabe, consiste en el pago de la suma de cuatro unidades de fomento por cada persona que el empleador contrate como reemplazante; cantidad que se debe repartir entre los trabajadores involucrados en la huelga (art. $381 \mathrm{CdT}$ ). Según se advierte, se trata de una estipulación que no guarda relación con una prestación efectiva de servicios, sino más bien, es un disuasivo para que el empleador no recurra a dicho reemplazo ${ }^{120}$. Pese a ello, teniendo en cuenta el concepto amplio de remuneración (art. $41 \mathrm{CdT}$ ), la Dirección del Trabajo entiende que dicho bono reviste tal naturaleza, pues considera que tiene como "causa el vínculo jurídico laboral existente entre el empleador y cada uno de los trabajadores involucrados en la negociación colectiva (...) y que no se encuentra incluido expresamente en el inciso $2^{\circ}$ del artículo 41 del Código del Trabajo como beneficio no constitutivos de remuneración" 121 .

En este contexto, volviendo a la retribución adicional de la invención mixta, si bien la actividad creativa del trabajador que le da origen nunca fue parte de las obligaciones del contrato y, por consiguiente, dicha retribución no tiene por objeto pagar servicios correlativos -lo que llevaría en principio a pensar que no es una remuneración-, no es menos cierto, que el derecho a retribución se genera para el trabajador por "causa del contrato de trabajo" (art. $41 \mathrm{CdT}$ ). Por tal motivo, concluimos que esta retribución debe ser también calificada como remuneración.

\footnotetext{
119 Véase, Gamonal (2008) 22-23.

120 Véase Gamonal Contreras, Sergio (2011). Derecho Colectivo del Trabajo. Santiago: AbeledoPerrot-LegalPublishing Chile, 521 pp., p. 403.

121 Dirección del Trabajo, Dictamen Ord. N 261/20, 24 enero de 2002.
} 


\section{CONCLUSIONES}

Concordamos en que la titularidad de la invención contratada o por encargo corresponda a la empresa, por tratarse de una consecuencia normal de la identificación entre invención y prestación contractualmente debida. En cambio, no estamos de acuerdo con que opere el mismo criterio tratándose de la invención mixta, toda vez que la actividad inventiva no forma parte de la obligación debida por el trabajador. El empleador debiera gozar de ciertos derechos sobre esta clase de invención -dado su aporte a su consecución, aun cuando se trató de uno no consciente-, pero no de una titularidad total sobre ellas, a menos que el trabajador así lo decida.

En relación con las invenciones contratadas o por encargo, las cláusulas que contemplen actividades inventivas muy amplias pueden llegar a significar que el derecho de los trabajadores a obtener sus propias invenciones - aquellas conocidas como "libres"- pueda resultar inoperante. De esta manera, se estaría afectando un derecho irrenunciable del trabajador.

La invención libre puede ser, o bien aquella realizada por un trabajador que no está obligado a desarrollar tareas de investigación, o bien aquella que consigue un trabajador que sí está contratado para realizar dichas tareas, pero que en este caso llevó a cabo por su cuenta otras investigaciones que no coinciden con las contratadas.

Dada la técnica legislativa utilizada, podría pensarse que tanto la retribución adicional de la invención contratada o por encargo como aquella de la invención mixta son el mismo estipendio, pero ello no es así, toda vez que presentan diferencias en cuanto a su procedencia y determinación. Con todo, las dos coinciden en que son remuneraciones, y no otra clase de desembolso.

Para que proceda la retribución adicional de la invención contratada, la aportación personal del trabajador ha de ir más allá de lo exigido en el contrato, y la importancia de la invención ha de ser mayor respecto de aquella a cuyo sostenimiento ya contribuye el empresario. Estas circunstancias cualitativas tienen unos contornos tan borrosos que será difícil que surja el derecho a esta remuneración.

Sobre la retribución adicional de una invención mixta, no puede hablarse de exceso de trabajo, sino más bien del desarrollo de una labor en paralelo a la contratada, cuyo resultado es la invención. Cualquiera sea la invención que se obtenga se devengará el derecho al trabajador a esta remuneración. 


\section{BIBLIOGRAFÍA}

Albiol Montesinos, Ignacio (1975). "Los inventos del trabajador, el socio industrial y la ejecución de obra". Revista de Derecho Privado, pp. 109-126.

Alonso Olea, Manuel (1987). "Invenciones laborales". En Alonso Olea, Manuel et al. Jornadas sobre la nueva ley española de patentes: Tecnologia, industria y patentes en la España comunitaria: ciclo de doce conferencias presentadas los dias 14 y 15 de mayo de 1986. Barcelona: Grupo español de la AIPPI, pp. 87-94.

Alonso Olea, Manuel y Casas Baamonde, María Emilia (2006). Derecho del Trabajo. 24a Ed. Madrid: Civitas, 1.289 pp.

Álvarez Montero, Antonio (2008). "Invenciones laborales. Un marco jurídico viejo para un nivel de investigación creciente". Trabajo: Revista andaluza de relaciones laborales, $\mathrm{N}^{\circ}$ 21. pp. 141-166.

Armando Grisolía, Julio (2008). Manual de Derecho Laboral. 4a Ed. Buenos Aires: LexisNexis, 1.053 pp.

Barreiro González, Germán (1981). Diligencia y negligencia en el cumplimiento. Estudio sobre la prestación del trabajo debida por el trabajador. Madrid: Centro de Estudios Constitucionales, 420 pp.

Baylos, Hermenegildo (1993). Tratado de Derecho Industrial. 2a Ed. Madrid: Civitas, $1.061 \mathrm{pp}$.

Bercovitz Rodríguez-Cano, Alberto (1976). "Anotaciones a la regulación legal española sobre invenciones laborales". Actas de derecho industrial y derecho de autor, T. III, pp. 49-91.

Bernhardt, Wolfgang y Krasser, Rudolf (1986). Lehrbuch des Patentrechts. 4a Ed. Munich: Beck, 741 pp.

Biblioteca del Congreso Nacional (1991). Historia de la Ley $N^{o}$ 19.039. Disponible en línea: http://www.bcn.cl/obtienearchivo?id=r ecursoslegales/10221.3/12821/5/HL19039.pdf [consultado el 19 de julio de 2011], 452 pp.

Blanco Jiménez, Araceli (1999). Protección jurídica de las invenciones universitarias y laborales. Pamplona: Arazandi, $345 \mathrm{pp}$.

Cuenca Alarcón, Miguel (2006). La determinación de la prestación de trabajo. Madrid: CES, 379 pp.

Diéguez Cuervo, Gonzalo (1995). Lecciones de Derecho del Trabajo. $4^{\mathrm{a}}$ Ed. Madrid: Marcial Pons, 790 pp.

Estupiñán CÁCEREs, Rosalía (2003). Las invenciones laborales en la empresa. Madrid: Edersa, 346 pp.

Fariña Quezada, Lautaro (2010). Regulación del sueldo en el Código del Trabajo. Santiago: LegalPublishing, $170 \mathrm{pp}$.

Feas Costilla, Javier (1987). "Las invenciones laborales en la ley de patentes de 1986". Revista del Trabajo, N87, pp. 121-136. 
Fernández Domínguez, Juan y Agra Viforcos, Beatriz (1997). "De las invenciones laborales". Tribuna social: Revista de seguridad social y laboral, $\mathrm{N}^{\circ} 83$, pp. 29-44.

Fisk, Catherine (1998). "Removing the 'Fuel of Interest' from the 'Fire of Genius': Law and the Employee-Inventor, 1830-1930". The University of Chicago Law Review, Vol. 65, No 4, pp. 1.127-1.198.

Gamonal Contreras, Sergio (2011). Derecho Colectivo del Trabajo. Santiago: LegalPublishing, $521 \mathrm{pp}$.

(2008). Fundamentos de Derecho Laboral. Santiago: LegalPublishing, 168 pp.

Gamonal Contreras, Sergio y Guidi Moggia, Caterina (2010). Manual del Contrato de Trabajo, Santiago: AbeledoPerrotLegalPublishing, 342 pp., p. 75. En el mismo sentido, Lizama Portal, Luis (2003). Curso de Derecho del Trabajo. Santiago: LexisNexis, 238 pp.

Gárate Castro, Francisco (1984). El rendimiento en la prestación de trabajo. Madrid: Civitas, 323 pp.

García Díaz, Margarita, e Hidalgo Rúa, Gloria (1996). "Invenciones y creaciones intelectuales: especial referencia al software". Acciones e investigación sociales, $\mathrm{N}^{\circ} 4$, pp. 81-91.

García VIDAL, Ángel (2007). "Las invenciones laborales libres y de servicio [Comentario a la sentencia de la Audiencia Provincial de Murcia, núm. 332/2006 (Sección 2a), de 12 de diciembre]”. Actas de Derecho industrial y Derecho de autor, T. XXVII (2006-07), pp. 621-644.

García-Huidobro Amunátegui, Vladimir (1992). Legislación sobre propiedad industrial. Análisis, jurisprudencia y guia práctica. Santiago: Editorial Jurídica de Chile, 279 pp.

Gómez Segade, José Antonio (1984). "El derecho a la patente". En Gómez Segade, José Antonio. y Fernández-Novoa, Carlos. La modernización del Derecho español de patentes. Madrid: Montecorvo, pp. 103-138.

(1998). "Remuneración por invenciones laborales y prescripción de acciones derivadas de la patente [comentario a la Sentencia de la audiencia provincial de Burgos de 20 de junio de 1997, "Azagra c. Rhone Poulenc Nutrición Animal, S.A.”]". Cuadernos de jurisprudencia sobre Propiedad Industrial, $\mathrm{N}^{\circ} 17$, pp. 13-27.

Gudmestad, Telje (1982). "Patent Law of the United States and the United Kingdom: A comparison". Loyola of Los Angeles International and Comparative Law Journal, $\mathrm{N}^{\circ}$ 5, pp. 173-196.

Guisado, Héctor (2010). "Capítulo IV. Desarrollo de la relación. A) Derechos y deberes de las partes". En Rodríguez Mancini, Jorge (director). Derecho del trabajo. Buenos Aires: Astrea, T. I, pp. 425494. 
Gridel, Jean-Pierre (1980). Les inventions de salariés à l'épreuve de la loi du 13 juillet 1978 et du Décret du 4 septembre 1979, París: Librairie générale de Droit et de jurisprudence, $79 \mathrm{pp}$.

Hershovitz, Marc (1995). "Unhitching the trailer clause: The rights of inventive employees and their employers". Journal of Intellectual Property Law, № 3, pp. 187-212.

Illescas Ortiz, Rafael (2010). "Lección 7a. El Derecho industrial y el régimen jurídico de la competencia”. En Jiménez SÁnchez, Guillermo (coordinador). Lecciones de Derecho Mercantil. 14a Ed. Madrid: Tecnos, pp. 126-149.

Johnstone, Bob (2007). Brilliant! Shuji Nakamura and the Revolution in Lighting Technology. Nueva York: Prometheus Books, 336 pp.

Lanata Fuenzalida, Gabriela (2006). Contrato individual de trabajo. $3^{a}$ Ed. Santiago: LexisNexis, 318 pp.

Lema Devesa, Carlos (1990). "Las invenciones laborales en la Ley de Patentes de 20 de marzo de 1986". En Bisval, J. y Viladás, C. (coordinadores). Derecho y Tecnología: Curso sobre innovación y transferencia. Barcelona: Ariel, pp. 145-156.

León Hurtado, Avelino (1983). El Objeto en los Actos Jurídicos. 2a Ed. Santiago: Editorial Jurídica de Chile, $151 \mathrm{pp}$.

Llompart Bennassar, Magdalena (2007). El salario: concepto, estructura y cuantía. Madrid: La Ley, 740 pp.

Lois Bastida, Fátima (1999a). "La atribución de los resultados de la investigación contratada en la Ley de Patentes". Anuario da Facultade de Dereito da Universidade da Coruña, No 3, pp. 331-349.

(1999b). "La protección del inventor asalariado en el Derecho brasileño". Actas de Derecho Industrial y Derecho de Autor, T. XX, pp. 1.553-1.568.

(2000). La protección del inventor asalariado. Madrid: Civitas, 290 pp.

Luque Parra, Manuel (2005). "La (re)definición del concepto de "trabajador" en el ámbito de las nuevas tecnologías a la luz del derecho de propiedad industrial y de propiedad intelectual", en Del Rey Guanter, S. (director) y Luque Parra, M. (coordinador). Relaciones Laborales y Nuevas Tecnologías. Madrid: La Ley, pp. 77-104.

Macchiavello Contreras, Guido (1986). Derecho del Trabajo. Santiago: Fondo de Cultura Económica, T. I, 546 pp.

Martín, Antonio et al. (2006). Derecho del Trabajo. 15a Ed. Madrid: Tecnos, $959 \mathrm{pp}$.

Melis Valencia, Christian (1997). “Cláusulas tácitas”. Boletín Oficial de la Dirección del Trabajo, N¹03, pp. 1-13.

Mercader Uguina, Jesús (2004). "Retribución variable y cambios productivos". En Aparicio Tobar, Joaquín. Estudios sobre el salario (coordinador). Albacete: Bomarzo, pp. 87-109. 
Merges, Robert (1999). "The Law and Economics of Employee Inventions". Harvard Journal of Law \& Technology, Vol. 13, No 1, pp. $1-54$.

Muosseron, Jean Marc (1984). Traité des Brevets. París: CEIPI, Vol. I, $1.097 \mathrm{pp}$.

Pedemonte Feu, Jorge (1988). Comentario a la Ley de Patentes. Barcelona: Bosch, 418 pp.

Pellisé Prats, Buenaventura (1985). Informe analítico sobre el Proyecto de Ley de Patentes de 1985. Barcelona: Centro de Estudios para el fomento de la investigación, $68 \mathrm{pp}$.

Pérez Pérez, Manuel (1994). Invenciones laborales de trabajadores, profesores universitarios y personal investigador. Madrid: Civitas, 397 pp.

Reitzle, Helmut et al. (2007). German Act on Employees' Inventions. Munich: Verlach C.H. Beck, 112 pp.

Rodríguez-Piñero y Bravo-Ferrer, Miguel (1986). "El nuevo régimen jurídico de las invenciones laborales". Relaciones Laborales, $\mathrm{N}^{\circ}$ 6, pp. 41-48.

Rojas Miño, Irene (2004). Manual de Derecho del Trabajo. Santiago: LexisNexis, 309 pp.

Roubier, Paul (1952-54). Le Droit de la Propriété Industrielle. París: Sirey, T. II, $854 \mathrm{pp}$.

Sala Franco, Tomas y Vicent Chuliá, Francisco (1988). "El nuevo régimen jurídico de las invenciones laborales". Actualidad Laboral, $\mathrm{N}^{\circ} 4$, pp. 1.977-1.999.

Savitsky, Thomas (1991). "Compensation for employee inventions". Journal of the Patent Office Society, N 73, pp. 646 ss.

SenA, Giuseppe (1990). I diritti sulle invenzioni e sui modelli industriali. $3^{\text {a }}$ Ed. Milán: Giuffrè, 674 pp.

Sierra Herrero, Alfredo (2005). "Ingenio y trabajo. Las invenciones laborales en el Derecho español y chileno". Revista de Derecho de la Universidad Católica del Norte, ańo $12 \mathrm{~N}^{\circ} 1$, pp. 121-155.

(2010). "Invenciones de los trabajadores a la luz de la ley de propiedad industrial". Revista de Derecho de la Empresa, No 24, pp. 73-82.

Trimborn, Michael (2009). Employees' inventions in Germany. Munich: Kluwer Law International, 196 pp.

Trigo García, María Belén (1999). Contrato de servicios. Perspectiva juridica actual. Granada: Comares, $424 \mathrm{pp}$.

Van Slyke, Paul y Friedman, Mark (1990). "Employer's rights to inventions and patents of its officers, directors and employees". American Intellectual Property Law Association Quarterly Journal, N $^{\circ}$ 18, pp. 127-154. 